\title{
MAMMARY EPITHELIAL CELL GROWTH ON A THREE-DIMENSIONAL SCAFFOLD IN AN OPERATING BIOREACTOR
}

\author{
A Thesis \\ Presented to the Faculty of \\ California Polytechnic State University, San Luis Obispo
}

\author{
In Partial Fulfillment \\ of the Requirements for the Degree \\ Master of Science in Engineering \\ with a Specialization in Biochemical Engineering
}

by

Melissa Marie DaValle

April 2011 
(C) 2011

Melissa M. DaValle ALL RIGHTS RESERVED 


\title{
COMMITTEE MEMBERSHIP
}

\author{
TITLE: MAMMARY EPITHELIAL CELL GROWTH \\ ON A THREE-DIMENSIONAL SCAFFOLD \\ IN AN OPERATING BIOREACTOR
}
AUTHOR:
Melissa M. DaValle
DATE SUBMITTED:
April, 2011
COMMITTEE CHAIR: Dr. Robert Crockett
COMMITTEE MEMBER: Dr. Kristen O'Halloran Cardinal
COMMITTEE MEMBER: Dr. Dan Walsh 


\title{
ABSTRACT
}

\section{MAMMARY EPITHELIAL CELL GROWTH ON A THREE-DIMENSIONAL SCAFFOLD IN AN OPERATING BIOREACTOR}

\author{
by \\ Melissa M. DaValle
}

Mammary epithelial cells are highly efficient secreting cells. With genetic engineering, the uses of these cells could be endless. Research is being conducted on these cells to determine their full potential to the biotech industry.

This paper investigates whether bovine epithelial mammary cells can survive in glutaraldehyde-treated gelatin tubes in an operating bioreactor. Many bioreactors were developed and tested to suit the needs of the cells. Procedures were created and carried out to ensure sterility of the bioreactors. Bovine mammary epithelial cells were implanted in the bioreactors and samples of their growth were taken over time. 


\section{ACK NOWLE DGE MENTS}

First, I would like to thank everyone in the General Engineering Department for helping me get where I am today. I would especially like to thank Dr. Crockett for his guidance throughout this project. I also would like to thank Danielle, Mollie, Chris, and Dr. Peterson for their support on this project as well.

Additionally, I would like to thank committee members Dr. Kristen O'Halloran Cardinal and Dr. Dan Walsh for their cooperation and input on the improvement of this thesis.

Furthermore, everyone at Cal Poly - friends, faculty, and staff - have made an impact on me that I will never forget.

My true gratitude goes to Mark, without whom I wouldn't have finished this paper. His undying support has and always will mean the world to me. 


\section{TABLE OF CONTENTS}

LIST OF TABLES ....................................................................................... vii

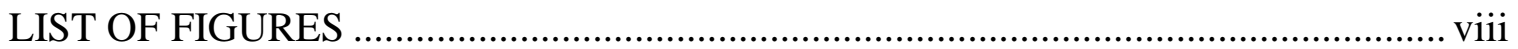

\section{CHAPTER}

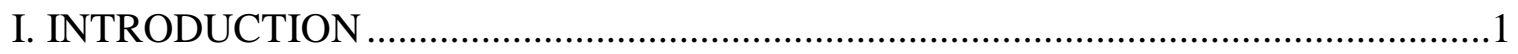

Mammary Cells and Their Function ..................................................1

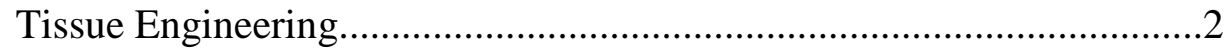

Cell Growth on Substrate..................................................................5

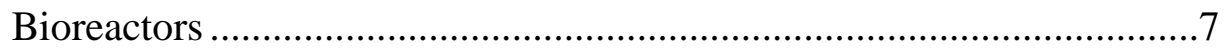

\section{TUBE STRUCTURE DEVELOPMENT}

Materials and Methods..........................................................................10

Results and Discussion ..............................................................13

III. BIOREACTOR

Materials and Methods...............................................................15

Results and Discussion ..................................................................20

IV. CELL SEEDING OF BIOREACTOR

Materials and Methods..............................................................22

Results and Discussion .............................................................26

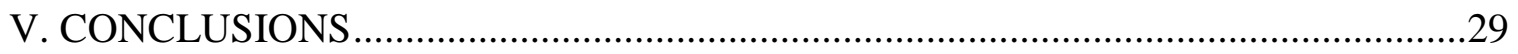

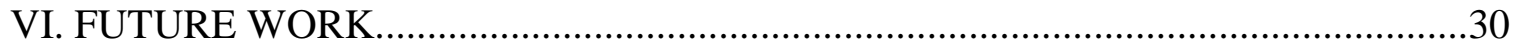

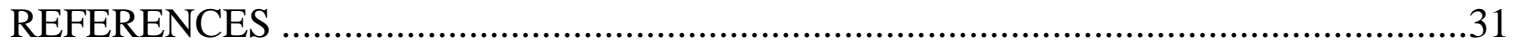

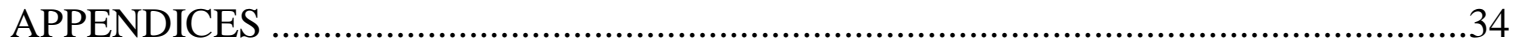

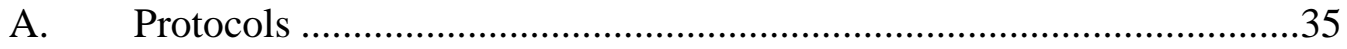

B. Additional Images of Cells .....................................................58 


\section{LIST OF TABLES}

Table 3.1 Table of Bioreactor Designs, with scored requirements (1=poor, 5=exemplary) ...........20 


\section{LIST OF FIGURES}

Figure 1.1 Macro and micro view of mammary gland......................................................... 1

Figure 1.2 Experiment demonstrating the necessity of the ECM ........................................ 4

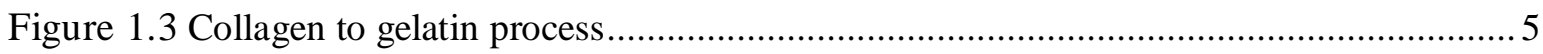

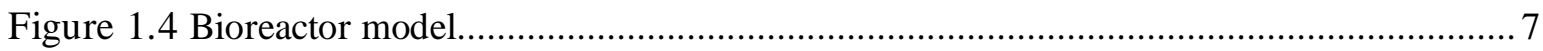

Figure 2.1 Valves and a Teflon rod used for tube construction............................................. 10

Figure 2.2 Autoclaved plastic casting block with 2 layers of sterile tape, ready for gelatin

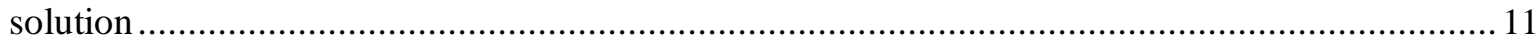

Figure 2.3 A dry, untreated gelatin tube wrapped around the Teflon rod-valve apparatus............ 12

Figure 2.4 Two views of glutaraldehyde treated gelatin tubes.............................................. 13

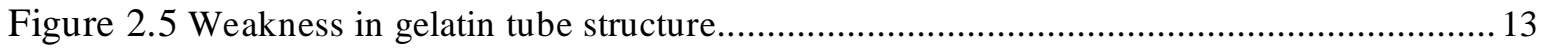

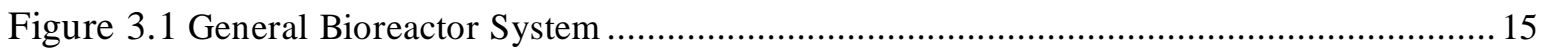

Figure 3.2 Design 1 (a) bioreactor container (b) preliminary sketch of set up of bioreactor .......... 16

Figure 3.3 Design 2: Cell Flask (a) bioreactor housing (b) preliminary model of bioreactor ......... 17

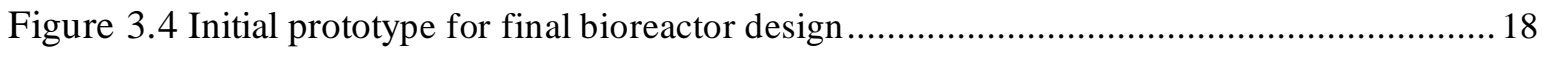

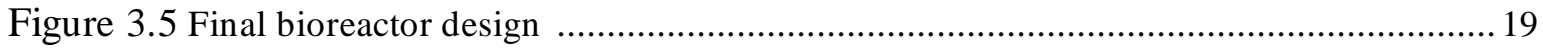

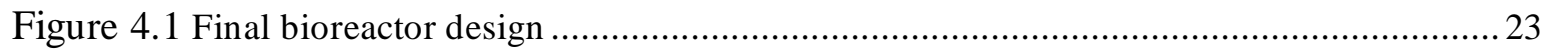

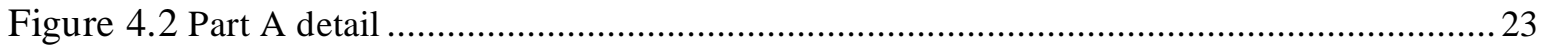

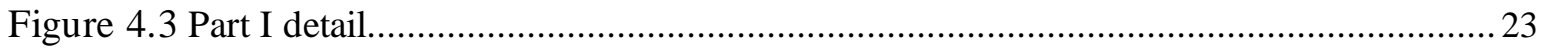

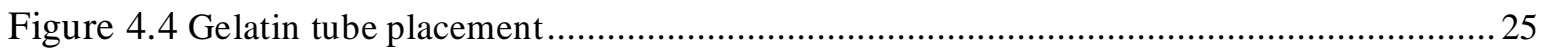

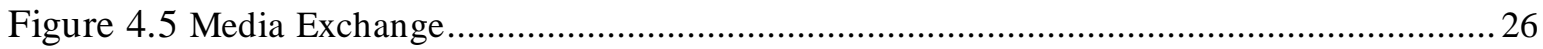

Figure 4.6 Two views of mammary call grow th on Petri dishes .......................................... 26

Figure 4.7 Mammary cell growth on treated gelatin tubes 2 days after implantation....................22

Figure 4.8 Mammary cell growth on treated gelatin tubes one week after implantation ................27 


\section{Chapter 1: INTRODUCTION}

"Biopharming" is the use of transgenic animals, plants, and bacteria to produce pharmaceuticals. This is an emerging field, with new advances occurring frequently. Pharmaceuticals produced by genes inserted into living things are an innovative idea, but can be difficult to perfect in practice. Mammary tissue is ideal for biopharming because of the ability to secrete, but the genetic engineering of mammals is expensive. Working with the cells in vitro reduces the possibilities of outside interactions affecting the system. This paper's emphasis is to determine if bovine epithelial mammary cells survive in glutaraldehyde-treated gelatin tubes in an operating bioreactor.

\section{MAMMARY CELLS AND THEIR FUNCTION}

A mammary cell is a specific epithelial cell with the ability to secrete milk proteins. Figure 1.1 depicts an individual alveolus and a gland. The mammary cells line the lumen of the alveolus.

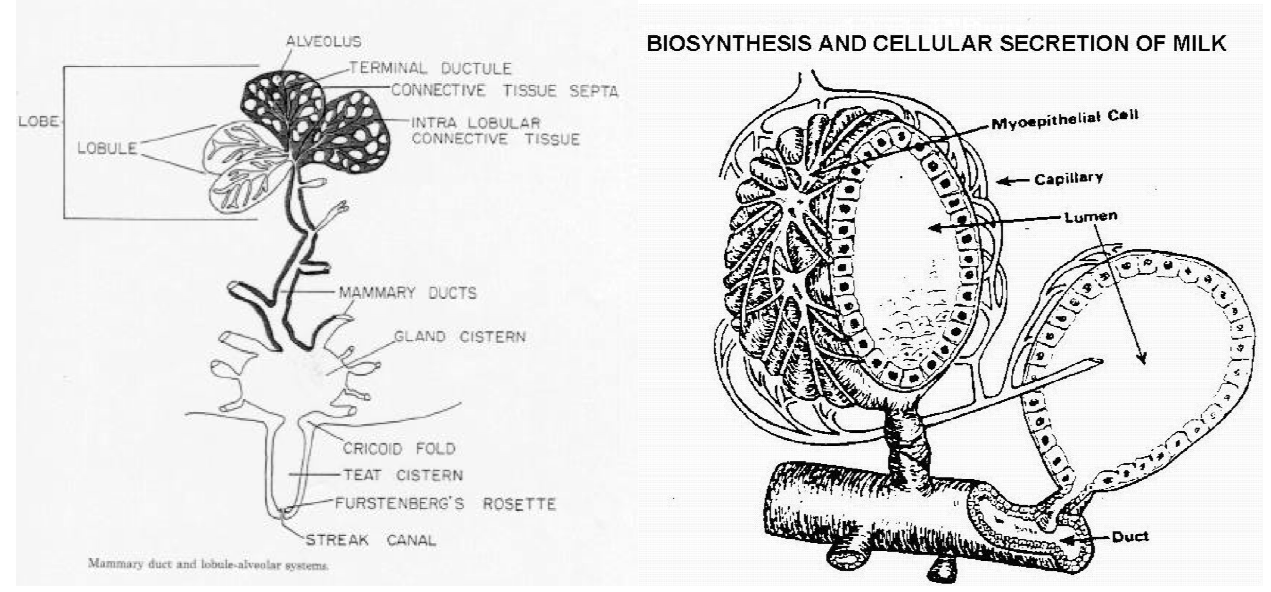

Figure 1.1 Macro and micro view of mammary gland [12]

The alveolus is then surrounded by myoepithelial contractile cells that aid in the movement of the milk proteins from the lumen to the ducts. The alveoli are all connected by a system of ducts to form a lobule. The lobules form a lobe, which combine to make 
the mammary gland. The milk is produced when the hormone oxytocin is released causing the epithelial cells to produce milk products (casein micelles, lactose, fat lobules, etc.). The milk then flows from the glands through ducts to the nipple [12].

The epithelial cells lining the lumen are polar by nature, meaning the opposing sides of the cell serve very different functions. This polarization must be present for the gland to function properly. Nutrients are taken in by one side and milk proteins are secreted from the other. The inside of the cell is polarized in a similar way with the nucleus on the basal (blood) side, accepting nutrients, and the contents responsible for the milk production on the apical (lumen) side [7]. The basal membrane is very important because it provides the structure for the alveoli and lobes. The extracellular matrix (ECM) is vital for holding the cells in place - promoting the functional and structural characteristics of the cells [5].

It is very important for the cell environment to be replicated in vitro. The geometry and scaffolding should mimic the in vivo conditions as much as possible. To make this possible, the basal and lumen sides of the cells must be recreated with nutrients on the outside and a simulated lumen space internally. This should provide the cells with the structure to secrete as they would normally.

\section{TISSUE ENGINEERING}

Tissue engineering is a rapidly evolving discipline that seeks to repair, replace, or regenerate specific tissues or organs by translating fundamental knowledge in physics, chemistry, and biology into practical and effective materials, devices, systems, and clinical strategies [11]. Tissue engineering is traditionally thought to focus on the development of in vitro bioartificial tissues, which are typically based on cells derived 
from donor tissue. The tissues can be used as transplants to improve biological function of the recipient. Typical tissues include skin, liver, pancreas, kidney, blood vessels, and bone. If done in vivo, local modifications are performed to alter cell growth and function [15].

Tissue engineering is the duplication of tissue, whereas protein production uses one particular cell type for producing specific proteins. Transfection is the introduction of foreign DNA into higher organisms, classifying them as transgenic animals. The animals are engineered to express a specific protein, releasing it into specific fluids such as milk or urine. This process is cost effective for complex proteins, but has unfavorable health effects for the host animal [15]. Another problem that can occur is that the posttranslation of the protein is not always complete, incurring more cost. Eliminating the effects to the animal and isolating the production zone increases the likelihood of the biologic system to persist. Mammalian cells grow slower, have more expensive media, and have lower protein expression than microbial growth, causing them to be more expensive overall. Mammalian cell culture is chosen when the virtual authenticity of the product protein must be complete [15].

Anchorage-dependent cells must spread on a substrate to proliferate and function. Most animal cells must attach to a surface to resume normal growth, and resume the three-dimensional environment [4]. Cell adhesion is mediated by extracellular matrix (ECM) proteins. The ECM has nonspecific cell surface receptors which facilitate adhesion; cell binding is more successful if specific receptors are present [15]. The ECM may contact the cells only at one surface, as is the case with epithelial and endothelial 
cells, or it may completely surround cells like chondrocytes. ECM components regulate differentiation and development of cells.

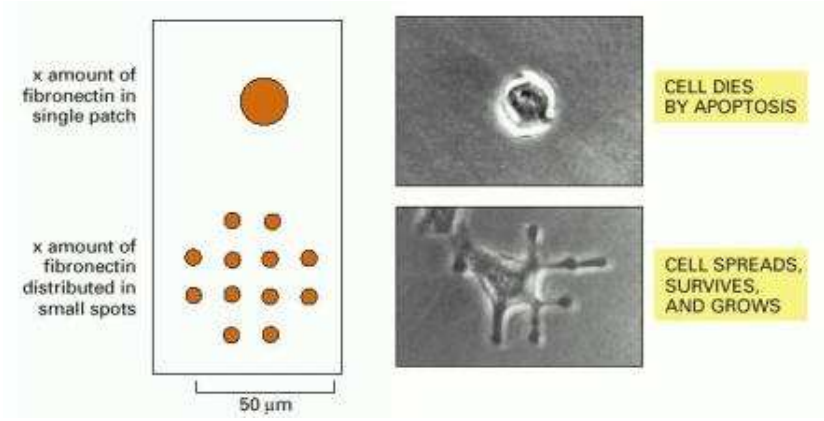

Figure 1.2 Experiment demonstrating the necessity of the ECM [3]

As seen in Figure 1.2, fibronectin (a component of the ECM) is necessary for the cell to survive and proliferate. Mammary epithelial cells assume the polarized phenotype and secrete milk proteins in vitro when cultured on reconstituted basement membrane or collagen gels [1]. Due to the critical nature of the ECM for cell function, a well-designed scaffold needs to be created to support the cells.

Three-dimensional porous scaffolds promote new tissue formation. They do this by providing a surface and void volume that promotes attachment, migration, proliferation, and desired differentiation of connective tissue progenitors throughout the region where new tissue is needed [11]. Several requirements have been identified as crucial for the production of tissue engineering scaffolds: (1) scaffolds should possess interconnecting pores to favor tissue integration and vascularization, (2) have appropriate surface chemistry to favor cellular attachment, differentiation, and proliferation, (3) possess adequate mechanical properties to match the intended site for implantation and handling, (4) be made from a biodegradable or bioresorbable material, that degrades at an appropriate rate with no undesirable byproducts, so that the tissue will eventually replace the scaffold, (5) be easily fabricated into a variety of shapes and sizes [13, 14]. 
Scaffolds are currently being made with a wide variety of materials: biological polymers, synthetic polymers, tissue-derived materials, ceramics or mineral-based matrices, metals, and composites of two or more materials [11, 13]. Collagen may be the ideal scaffold material as it is the major component of the ECM. It provides a more native surface, relative to synthetic polymers, favoring cellular attachment as well as being chemotactic to cells. Also, collagen substrates can modify the morphology, migration and in certain cases, the differentiation of cells. Collagen is relatively easy to fabricate into structures using freeze-drying and critical point drying techniques [14]. Other scaffold fabrication techniques include gas foaming, fiber bonding, melt molding, and solution casting [13].

\section{CELL GROWTH ON SUBSTRATE}

Gelatin is derived from collagen. Collagen is tightly coiled polypeptide chains formed into a triple helix. The collagen goes through the process of hydrolysis to

Figure 1.3 Collagen to gelatin process [17]

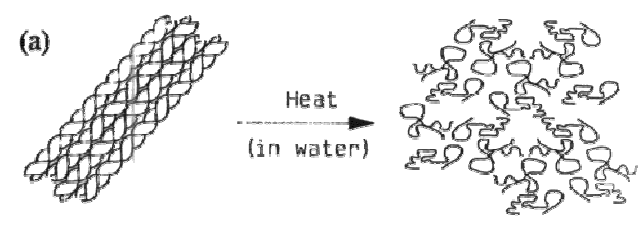

(b)

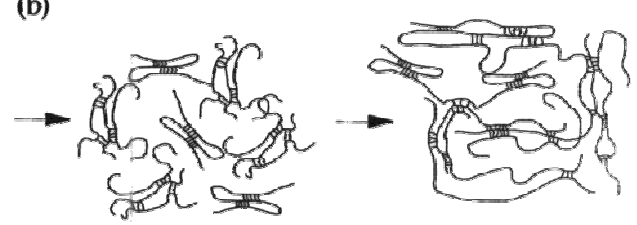

Cooling

Gelatin Farmation

degrade it into gelatin. Collagen is very strong and is present in most connective tissues and support structures. Gelatin is essentially a weakened form of collagen, in that it is denatured into a matrix of the single strands of collagen $[9,17]$. Figure 1.3 illustrates the collagen and gelatin structures.| Gelatin is not nearly as strong as collagen, but it has its 
own advantages, the most important of which being added flexibility. Collagen is a naturally occurring substance; therefore it, as well as gelatin, are biocompatible and can be used as a scaffold in tissue engineering [10].

Gelatin in its natural state would degrade in the $37^{\circ} \mathrm{C}$ environment that is required to support mammary cells. The gelatin needs to be strengthened to survive. The way to do this safely, with little residual affects, would be to use glutaraldehyde. Glutaraldehyde is an organic compound that is used as a covalent cross-linking agent [15]. When it is used to cross-link collagenous tissues, biodegradation is reduced and strength and flexibility are preserved $[8,18]$. Glutaraldehyde is advantageous in that it works quickly and reacts with a large amount of amino acids, resulting in a more tightly cross-linked network. It is also less expensive, readily available, and is highly soluble in aqueous solution. Glutaraldehyde can be crosslinked with collagen, resulting in a more stable matrix compared to other aldehydes. Glutaraldehyde also acts as a sterilant, showing resistance to bacteria and fungi. Gelatin treated with glutaraldehyde is known to support cell growth with no adverse effects on cell morphology or growth. After treatment, the gelatin must be thoroughly rinsed, eliminating any cytotoxic effects [8].

The structure of the treated gelatin needs to be similar to the extracellular matrix (ECM) of the cell [14]. The ECM provides support, protection, and also aides in communication between cells. Creating a stable three-dimensional structure similar to the in vivo environment is essential for cell proliferation and vital to the functionality of the cells. The thickness of the matrix plays a large role as well, in that a thin matrix is less durable and a thick matrix has limited diffusion [15]. A tube configuration of a thin gelatin film provides the 3D structure for the cells and allows for the movement of 
nutrients [2]. The tube structure, along with defined, controlled surroundings simulates the in vivo environment needed to survive.

\section{BIOREACTORS}

A bioreactor is a device used to generate a product using a biological system. The graphic below (Figure 1.4) illustrates the general form of a bioreactor system [6]. This model illustrates the different factors which influence the performance of a bioreactor.

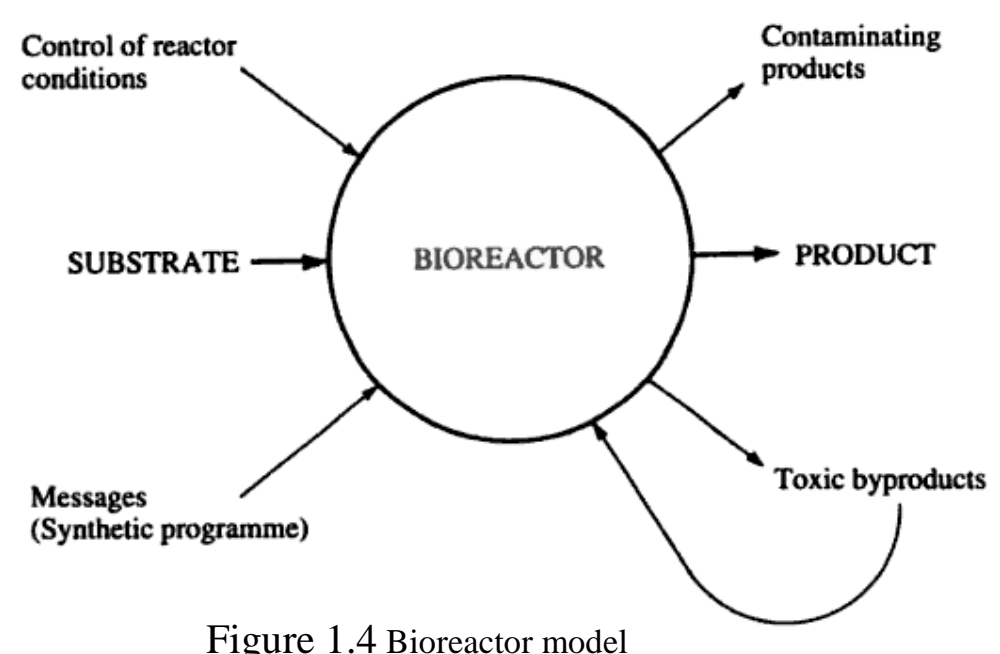

According to the article Flow Modeling in a Novel Non-Perfusion Conical Bioreactor, an ideal bioreactor has the following functions: (A) establish a uniform distribution of cells on a three-dimensional scaffold; (B) maintain the desired concentration of gases and nutrients in the culture medium; (C) provide efficient mass transfer to the growing tissue; (D) expose developing tissue to physical stimuli; (E) ease of usability, maintenance, and sterilization and $(\mathrm{F})$ provide information regarding the formation process of $3 \mathrm{D}$ tissues, which originate from the isolated cells; $(\mathrm{G})$ be cost effective with respect to up-scaled designs [16]. Most bioreactors can meet many of these functions, but it is difficult to optimize each category, especially with regards to the cost effectiveness. 
Bioreactors provide an environment that stimulates the growth of mammalian, bacterial, fungal, and yeast cells to produce a specified product. Homogeneity in regards to temperature, $\mathrm{pH}$, and nutrients can be simulated within a bioreactor, allowing cells to thrive [4]. There are many types of bioreactors, but only a few are used with mammalian cells. Animal cells have no cell wall; therefore they are more fragile and are sensitive to the shear forces inside a bioreactor. This also complicates the design of large-scale bioreactors for animal cells. Animal cells also require much less oxygen compared to plant and microbial cells, therefore less aeration is needed [15]. Cells can be grown in suspension or immobilized on walls or scaffolds.

With animal cells, immobilization is beneficial because it reduces the need to filter out cells post-production, more cells will be produced, as well as the fact that immobilized cells can carry out production of more complex products. Immobilization has its drawbacks in that it is difficult to control the microenvironments of the cells and the product needs to be secreted by the cell. Diffusion limitations are also a concern in that cells may be overcrowded, depriving themselves of nutrients. In addition, diffusion may be difficult if the actual surface the cells are growing on has limited porosity [15]. Diffusion is vital to deliver nutrients to the cells, but it also plays an important role in delivering the product.

Once a product has been secreted or produced by a cell, post-production work must be completed. Depending on the cell and product, a wide variety of processes may need to be completed to obtain the product. Products may include the biomass itself or an extracellular or intracellular component. 
Depending on the intended use of the product, a high level of purity may be required. Most mammalian products are extracellular and soluble. For example, antibiotics and enzymes are two products that commonly exhibit those features. Processes used to recover these include extraction, adsorption, ultrafiltration, and chromatography. Proteins need to be separated slightly differently in that organic solvents or salts may need to be added to precipitate out from the media. For any product, drying, and possibly crystallization, will need to occur [15]. Animal cells produce proteins that usually do not need further alteration besides purification because of their ability to process the complex proteins. Purification is complex because the other protein by-products generated by the cells are intermixed with the product of interest. Additionally, the serum from the growth media is an inexact mixture of nutrients and proteins that need to be extracted. The required purity makes a large impact on how long a product will take to process, as well as how much it will cost to produce. 


\section{Chapter 2: TUBE STRUCTURE DEVELOPMENT}

The tube structure is vital for the cell bioreactor system to work properly. It must be stable enough for cell adhesion and it needs to be able to maintain its structure in the fluid environment. It also needs to have a porous surface for diffusion, which is one of the reasons gelatin was chosen for this system.

\section{MATERIALS AND METHODS}

Previous work was done to find what the best concentration of gelatin would be for the tubes. In earlier research, it was found that either a 5\% or 7\% concentration of gelatin (to MilliQ water) would be the best to work with. Those concentrations provided sheets that were not too brittle to handle and dried into an even surface. The original gelatin films were cast into squares $(30 \mathrm{~cm} \times 30 \mathrm{~cm})$ with 1 milliliter of gelatin solution in each square.

It was found the squares would provide too much overlap for the existing parts that were going to be used in the bioreactor. The existing parts for the bioreactor are seen in Figure 2.1 below. A Teflon rod provides a base structure for the two valves, and allows for tube assembly.

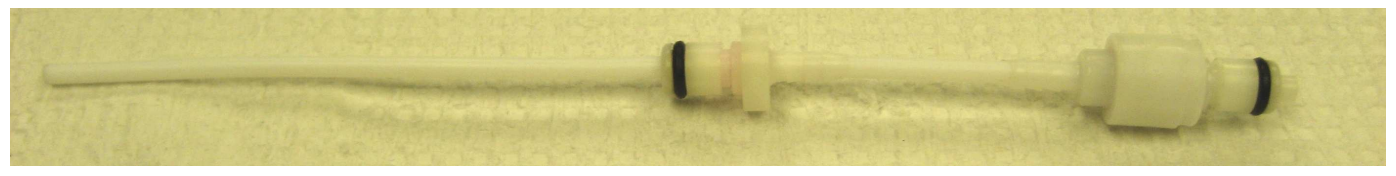

Figure 2.1 Valves and a Teflon rod used for tube construction

The circumference of the valves was about .39 " or $1 \mathrm{~cm}$. The width of the tube needed to have a slight overlap for construction purposes, which led to the use of a $2 \mathrm{~cm}$ width. That was later revised to $1.8 \mathrm{~cm}$ to reduce the overlap to ensure proper diffusion could take place. The width could not be reduced much more because it would be difficult constructing the tubes. The length was found to be a maximum of $4.5 \mathrm{~cm}$ because of the bioreactor constraints; which was later revised to $4.0 \mathrm{~cm}$. The gelatin films were cast on 
autoclaved polycarbonate blocks that were aseptically assembled in the hood with 2 layers of sterile tape (Figure 2.2).

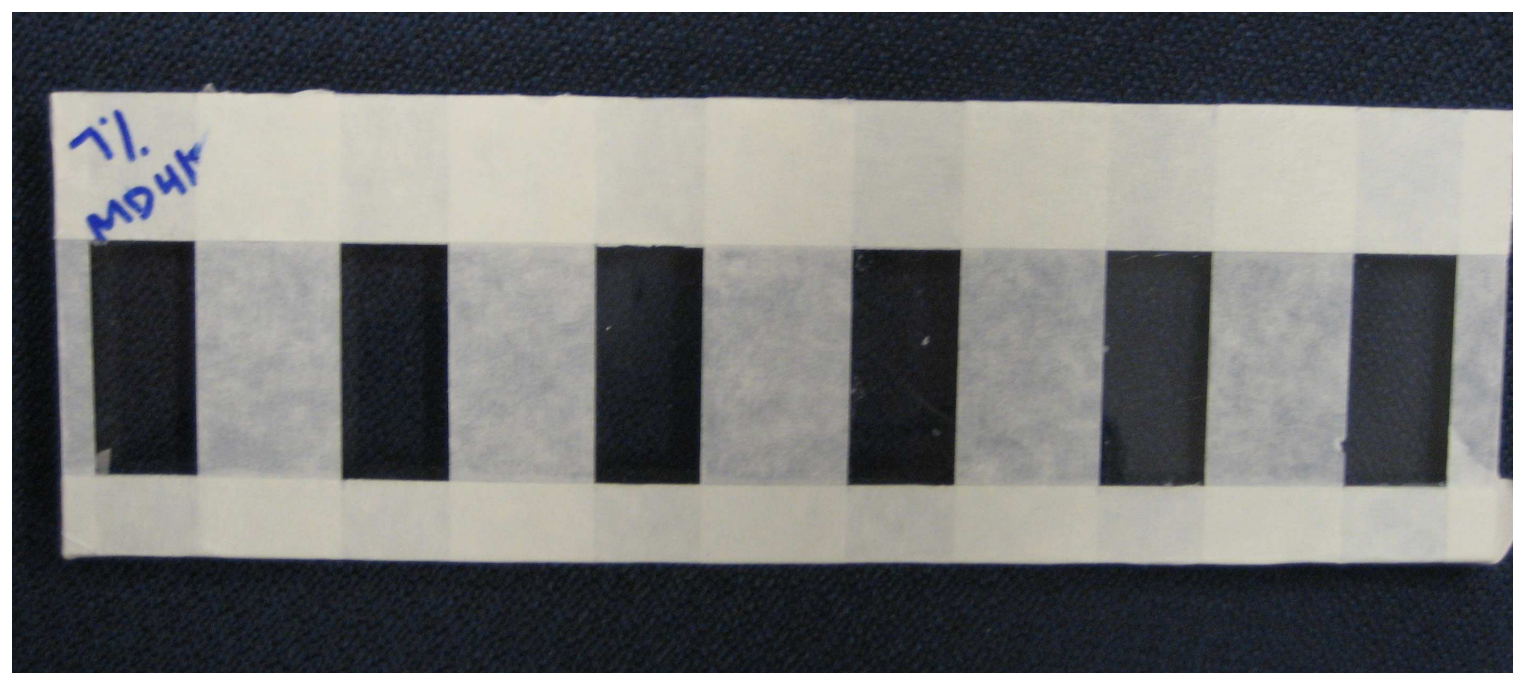

Figure 2.2 Autoclaved polycarbonate casting block with 2 layers of sterile tape, ready for gelatin solution

The previously found baseline for the gelatin was used to find the new amount of solution to use $(0.8 \mathrm{~mL})$ per square.

$$
\text { Baseline } \rightarrow \frac{900 \mathrm{~mm}^{2}}{1 \mathrm{~mL}}=\frac{\text { area of section }\left(\text { in } \mathrm{mm}^{2}\right)}{\text { new volume }}
$$

It was decided that one of the two gelatin concentrations needed to be selected to provide consistency for the rest of the experiment. The $7 \%$ gelatin concentration was selected because it was slightly easier to work with; it seemed to be more durable. The complete protocol for creating untreated gelatin sheets (for the tubes) can be found in Appendix A.

The actual tube assembly process is a critical step in the process of creating the bioreactor system and needs to be done very carefully. Once the sheets (40mm x 18mm) are dry, they are ready to be formed into a tube. The sheets need to be rehydrated which causes them to be susceptible to tearing because they have not yet been treated with glutaraldehyde. The tubes need to be formed with as few air bubbles as possible and with 
a tight seal around the valves. If the seal is not tight from the beginning, the cells will most likely leak out. Once the gelatin sheets are placed around the autoclaved Teflon rod-valve apparatus, complete drying of the tubes is necessary otherwise the structure may come apart during the treatment phase. Figure 2.3 shows a dry untreated gelatin tube.

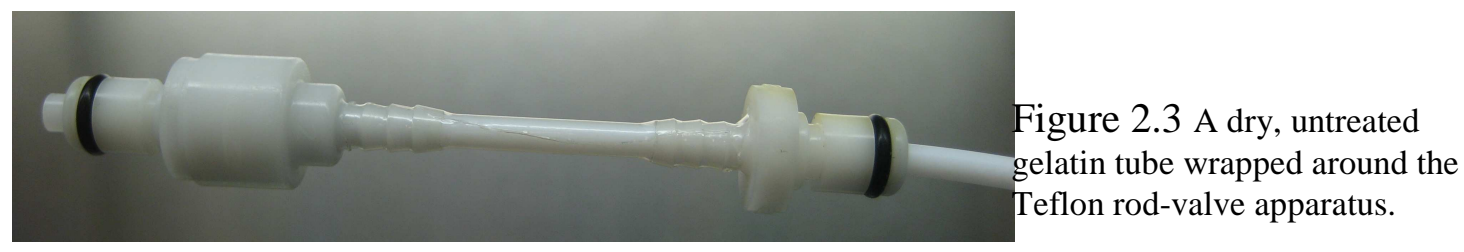

The complete protocol for rolling the untreated gelatin sheets into tubes can be found in Appendix A.

The next step for creating the gelatin tubes that are to be placed in the bioreactor would be the glutaraldehyde treatment. The treatment creates the cross-linking necessary for the gelatin to survive in the $37^{\circ} \mathrm{C}$ environment as well as provides an extra step of sanitation. Particular concentrations of glutaraldehyde, $0.1 \%$ or $0.3 \%$, were previously determined as viable. A detailed protocol was also created for treating gelatin films, but it was determined that treating the gelatin in tube form would be the better method. The treatment process is long, ranging from 9 to 10 hours depending on how many items are being treated. The process has a short time period (20 minutes) of exposure to the glutaraldehyde solution, with the rest of the time spent rinsing the glutaraldehyde from the apparatus and gelatin. The whole process uses agitation to ensure complete removal. If there is any residual glutaraldehyde on the gelatin tube, the mammary cells will be destroyed. Once the tubes have dried for at least 24-48 hours, the Teflon rod needs to be removed. The gelatin is still brittle even though it has been treated with glutaraldehyde, so the rod needs to be removed carefully. If the tube is not completely dry, the gelatin 
will have too much friction with the Teflon rod and will tear. The treated gelatin tube, with the Teflon rod removed can be seen in Figure 2.4 below. The complete protocol for treating the gelatin tubes in glutaraldehyde can be found in Appendix A.
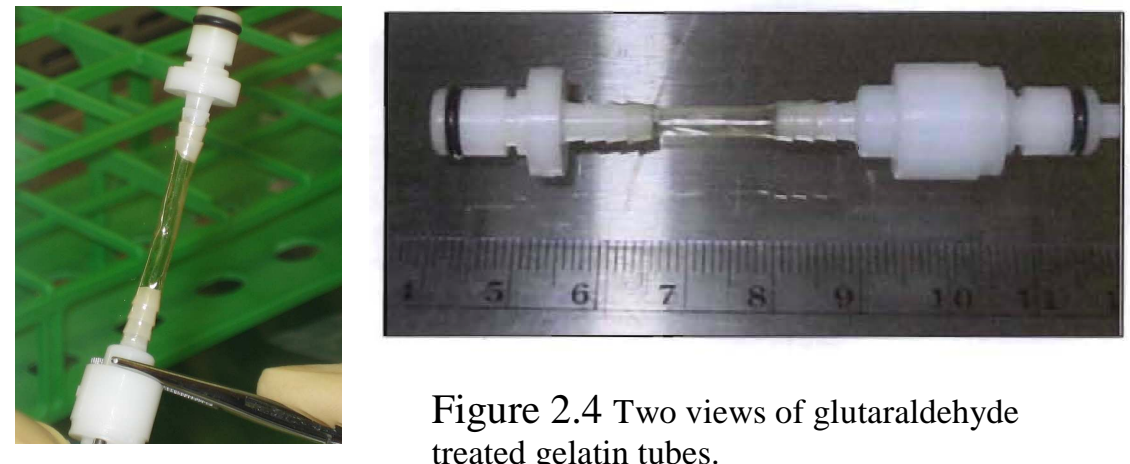

Figure 2.4 Two views of glutaraldehyde treated gelatin tubes.

\section{RESULTS AND DISCUSSION}

Placing the gelatin film around the Teflon rod-valve apparatus is one of the best options for the gelatin tube because it provides a consistent amount of material throughout the whole tube. Also, it is easier than trying to build a three-dimensional tube with no support structure. One of the biggest difficulties and weaknesses of placing the gelatin film around the tube is the seam around the valves (denoted by the arrow in Figure 2.5 below).

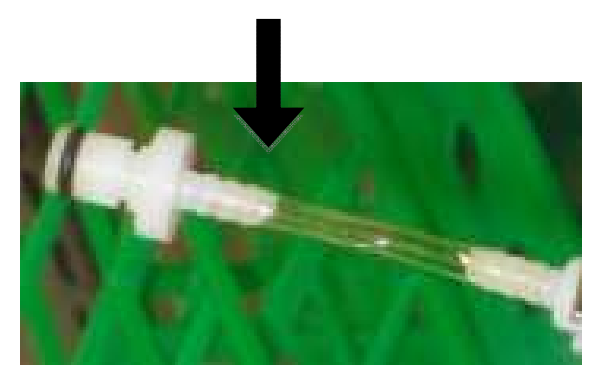

Figure 2.5 Weakness in gelatin tube structure

Once the treated gelatin tube (with the rod removed) becomes moist and filled with fluid, the pressure may cause a leak. If the gelatin sheet was placed correctly, leaks will likely not occur. The treated tube, when moist, is actually more durable than when dry; it has some give and take and is almost elastic in nature. The glutaraldehyde breaks down the 
gelatin over time so a two-week shelf life was determined to be the limit. No testing was done to establish the exact time of decay, but it was done as a precaution. 


\section{Chapter 3: BIOREACTOR}

The treated gelatin tubes need an environment that will allow for cell survival. Several criteria had to be met for the system to work:

- Holes needed for gas exchange

- Smallest amount of moving the gelatin tube as possible

- Sterile environment

- Small storage area for media, limits how much media is used at one time

- Fluid in/out for surrounding media

- Fluid in/out for gelatin tube

- Hold the predetermined tube-valve structure

\section{MATERIALS AND METHODS}

Three bioreactor designs were considered for the experiment. All the above criteria needed to be met in some capacity. Each design was then evaluated based on how well it would fulfill the criteria (see Table 3.1 in the next section). Figure 3.1 shows the basic system for the bioreactor. The simplified picture shows ports for the media to be exchanged from the system, as well as a way for the cells to be inserted and the saline solution to be circulated.

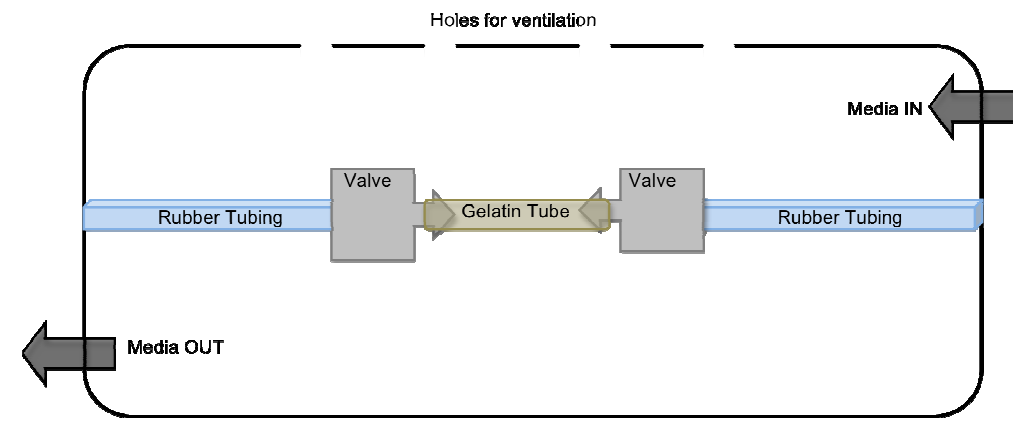

Figure 3.1 General Bioreactor System 
The first design was a plastic container with lid. The container looked similar to that of the one in Figure 3.2(a) and had a capacity of 500 milliliters. Figure 3.2(b) is a sketch of how the container would be modified to perform as a bioreactor. Holes were to be drilled in the top and some sort of structure was to be provided for the tube to sit in.

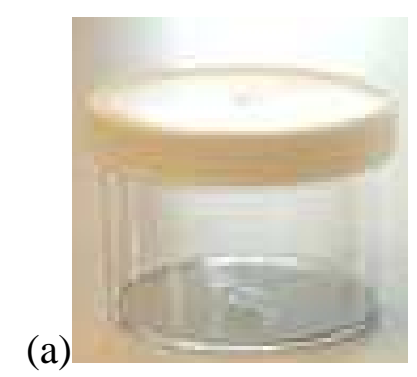

(b)

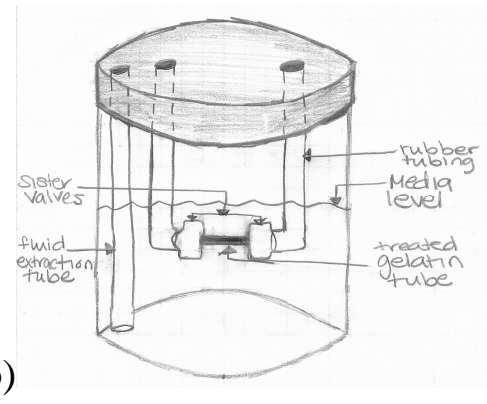

Figure 3.2 Design 1 (a) bioreactor container (b) preliminary sketch of set up of bioreactor

This design was quickly eliminated for many reasons. The capacity was too large; changing the media would mean using at least $200 \mathrm{~mL}$ of media every 3-4 days. If a smaller container was used, the problem created was that building a structure for the tube to sit in with the ability to have an in/out mechanism increases in difficulty. Additionally, a pump would probably be necessary to get fluid flow through the gelatin tube. One positive to this design would have been the removable lid because it would have allowed for easier assembly; however the drawbacks of this design outweighed this positive aspect.

The next design that was considered used a cell flask for the bioreactor. Several varieties of flasks were researched, but a basic tissue culture flask from Techno Plastic Products (TPP) with a re-closable lid was thought of for the next bioreactor design possibility. The flask from TPP is shown in Figure 3.3(a) and a mock up of the bioreactor for the cell flask is pictured in 3.3(b). 
The tissue culture flask in Figure 3.3(b) is a general flask (with similar dimensions) that had the top layer of plastic removed, and is not the flask from TPP. The cell flask model was also dismissed after further examination for several reasons:

(a)

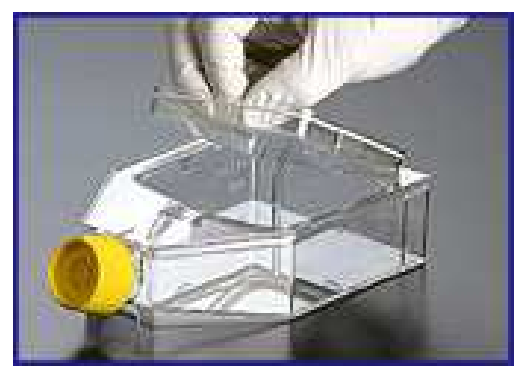

Figure 3.3 Design 2: Cell Flask

(a) bioreactor housing (b) preliminary model of bioreactor

(b)

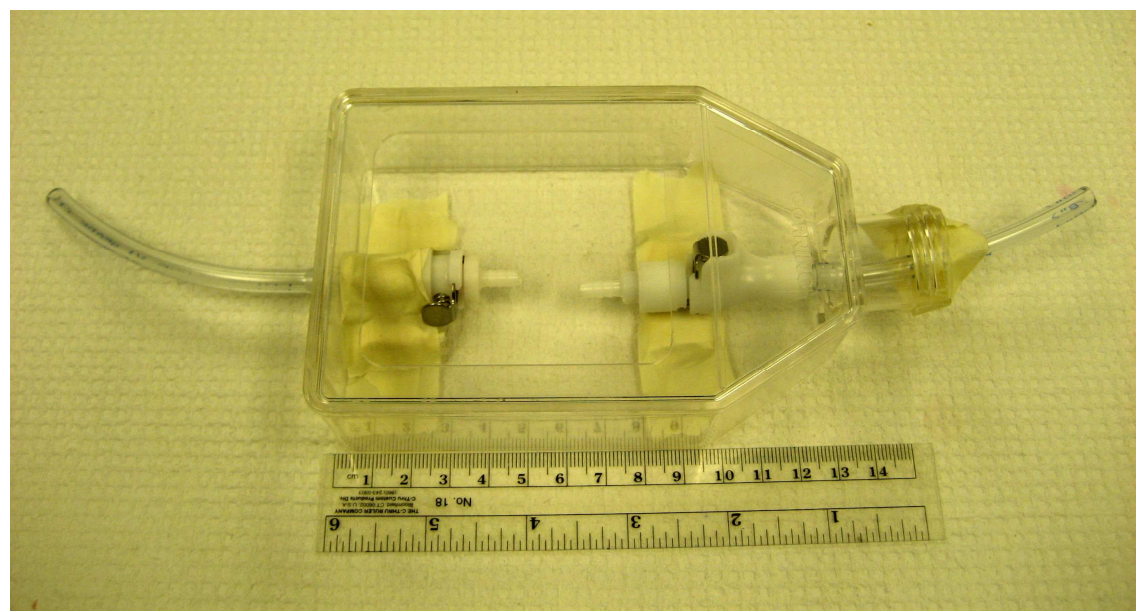

There was a concern that for the media to completely cover the gelatin tube, the cell flask would need to be at a maximum capacity or more. The capacity for the flask is $100 \mathrm{~mL}$, which did not provide a substantial reduction from the previously considered design. Another concern was that the lid to the flask would need to be altered to allow a tube to run through. The lids are specifically designed for gas exchange and altering them might, in turn, alter the functionality of the system. Attempts to drill holes for the in/out tubing showed that the plastic was prone to cracking. A single crack would ruin the flask and a new one would need to be constructed. The shape of the flasks would allow the flasks to 
stack during storage. That advantage, as well as the removable lid (for assembly reasons), were great assets, but the limiting factor was the capacity of the flask.

The final design proved to be the best. The base of the bioreactor is a $50 \mathrm{~mL}$ Falcon tube. Holes were drilled in the lid and through the bottom for the tubing to run through. Right away this seemed to be the best design because of the limited amount of media it needed. Using the Falcon tube also gave the advantage of an inexpensive base, which would allow for easy modifications, thus limiting the worry and expense created by mistakes during the construction process. This design also had the advantage of using gravity for the media exchange. Figure 3.4 is a photo of one of the initial prototypes for the final design.

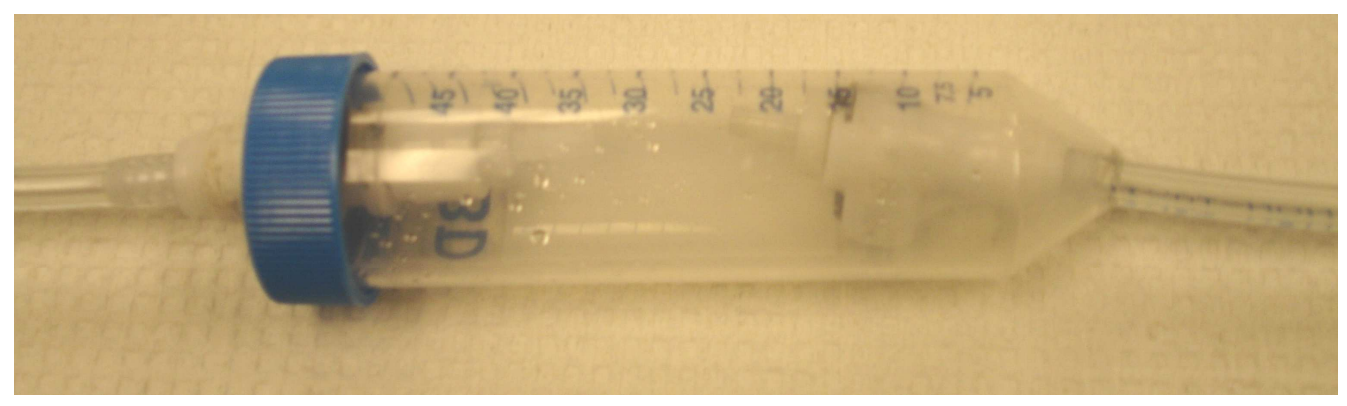

Figure 3.4 Initial prototype for final bioreactor design

The initial prototype was fairly easy to manufacture which would mean many could be produced for use at one time. Some aspects of the initial design showed cause for concern. For example, the bottom of the bioreactor was sealed was by pulling the tubevalve connection tight, creating a compression seal. The gelatin tube was inserted prior to creating this seal. This puts strain on the gelatin tube, which could lead to breaking it; some method should be determined to reduce the strain. Another feature, or features, that needed to be added was for the media exchange. Ideally, the media exchange should disturb the gelatin tube the least amount possible. Seeding of the mammary cells into the gelatin tubes is the most important part of the process because, without the cells, the 
bioreactor is useless. Chapter 4 will focus on general cell seeding and media as well as the specifics for the bioreactor.

The initial prototype needed a lot of work to become a functional bioreactor. There needed to be holes for gas exchange, and the lid was deemed to be the most appropriate place. Small holes were drilled around the top. Because of this, the bioreactor would need to be vertical so a test tube rack was used to hold the bioreactors in place. It was also decided there would be two valves on the bioreactor, one above the media level and one at the bottom to be used for media exchange. An IV clamp was added onto the lower tube because of the cell seeding (discussed in Chapter 4 along with detailed description of bioreactor). Figure 3.5 shows a fully assembled bioreactor ready for sterilization and then cell seeding.

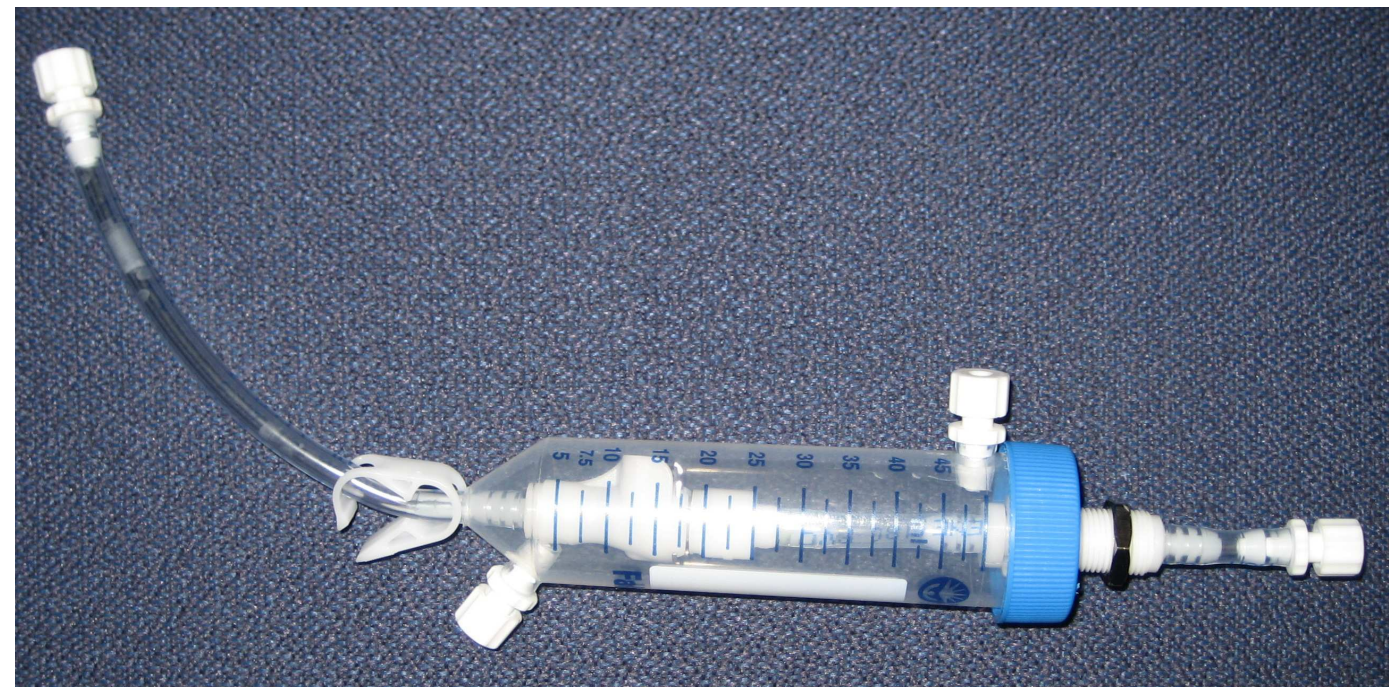

Figure 3.5 Final bioreactor design There were still concerns with the leaking and the fragility of the gelatin tubes, but by carefully following the proper procedures, there would be few problems. Aspects of the final design were discussed with Christopher Heylman, who wrote a detailed paper on the final bioreactor design. He also created protocols for bioreactor assembly, bioreactor 
sterilization, cell seeding of the bioreactor, and media exchange of the bioreactor. The revised protocols used in this case can be found in Appendix A.

\section{RESULTS AND DISCUSSION}

The three designs fulfilled the needs in different ways. Some of the designs met more of the needs than others. The needs were: holes for gas exchange, smallest feasible amount of movement of the gelatin tube, sterile environment, a small storage area for media, fluid in/out for surrounding media, fluid in/out for gelatin tube, and to be able to hold the predetermined tube-valve structure. Another thing that became important was the ease of the assembly process. Table 3.1 below shows a summary of the three designs.

Table 3.1 Table of Bioreactor Designs, with scored requirements ( $1=$ poor, $5=$ =xemplary)

\begin{tabular}{|l|c|c|c|c|c|c|}
\hline $\begin{array}{l}\text { Bioreator } \\
\text { Design }\end{array}$ & $\begin{array}{c}\text { Fluid } \\
\text { Capacity }\end{array}$ & $\begin{array}{c}\text { Approximate } \\
\text { Size }\end{array}$ & $\begin{array}{c}\text { Gas } \\
\text { Exchange }\end{array}$ & $\begin{array}{c}\text { In/out } \\
\text { Capacity }\end{array}$ & Usability & $\begin{array}{c}\text { Average } \\
\text { Score }\end{array}$ \\
\hline Design 1 & 1 & 1 & 2 & 1 & 4 & $\mathbf{1 . 8}$ \\
\hline Cell Flask & 2 & 2 & 2 & 2 & 2 & $\mathbf{2 . 0}$ \\
\hline Falcon Tube & 5 & 4 & 4 & 4 & 3 & $\mathbf{4 . 0}$ \\
\hline
\end{tabular}

The table shows the most important requirements and each design's respective performance on a scale from 1 to 5,1 being poor and 5 being exemplary, to evaluate each of the designs. The first design had a high rating in usability, meaning how easy it would be to manufacture and use with the gelatin tubes. It was never fully built, but the speculation was that the lid would make it easy to move around and assemble. The design did not do very well with the other important aspects, giving it an average score of a 1.8. The cell flask design also scored below what was preferable for the bioreactor in every category causing us to look for a more complete design. This led us to the final design using the Falcon tube. The fluid capacity scored high because to fit all the tubing and valves into one place, the area was just the right size. If the space was smaller, everything might not have fit as well. The usability is not very high because of the 
aseptic cell seeding process (see Chapter 4), but the Falcon Tube design outscored the other two designs and met the needs we felt were most important. 


\section{Chapter 4: CELL SEEDING OF BIOREACTOR}

The next step in the process was to merge the mammary cells with the bioreactor. The mammary cells needed to be grown separately in Petri dishes and then implanted into the gelatin tube in the bioreactor.

\section{MATERIALS AND METHODS}

The first step in the seeding of the bioreactors is to grow the mammary cells. A highly concentrated tube of cells is thawed, diluted, and placed into Petri dishes. The cells are fed with special media every 2-3 days and kept in an incubator at $37^{\circ} \mathrm{C}$. The goal is to grow the cells to confluence, which then allows the cells to be split to make more plates of cells or, for our purposes, be implanted into the bioreactors. The full protocol is listed in Appendix A under "Protocol for Plating, Splitting/Passaging, and Freezing of Cells".

Various types of media are used for different purposes when used with the cells. The first type of media, which is the basis for the other types of media and is not directly added to the cells, is called the basal media. The basal media starts from a powder or liquid base and MilliQ water. Other ingredients are added and the $\mathrm{pH}$ is adjusted to the optimal level of 7.0 to 7.10. The mixture is then filtered aseptically and placed into an autoclaved bottle. This basal media can be stored in the refrigerator for a few months and will be used as the foundation for the other cell medias (see Appendix A for various cell media protocols).

Other cell media are prepared from the basal media and will be used with cells. The shelf life for the media is only about two weeks; only small quantities should be prepared so there is no waste. The first is a basic, regular media that uses the basal media 
and has Fetal Bovine Serum (FBS) and antibiotics added, used for maintaining cells. The next is a growth media that adds insulin and progesterone to the FBS and antibiotics. The last type of media is lactation media, which has a hormone that promotes lactation in the mammary cells. The growth media would be the first to be used in the bioreactor and once the cells reach confluence in the gelatin tube, lactation media can be added.

The bioreactor needs to be an environment suitable for cell growth, maintenance, and production. The following is a detailed description of the bioreactor:

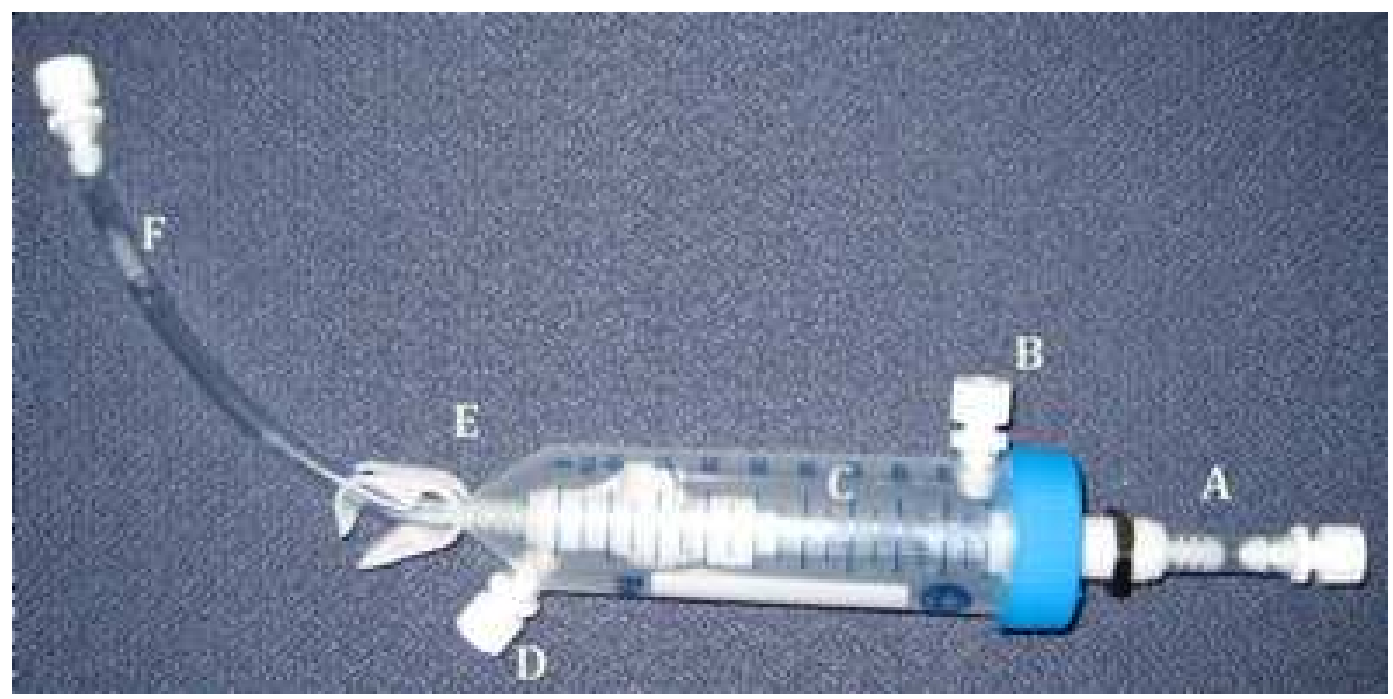

Figure 4.1 Final bioreactor design.

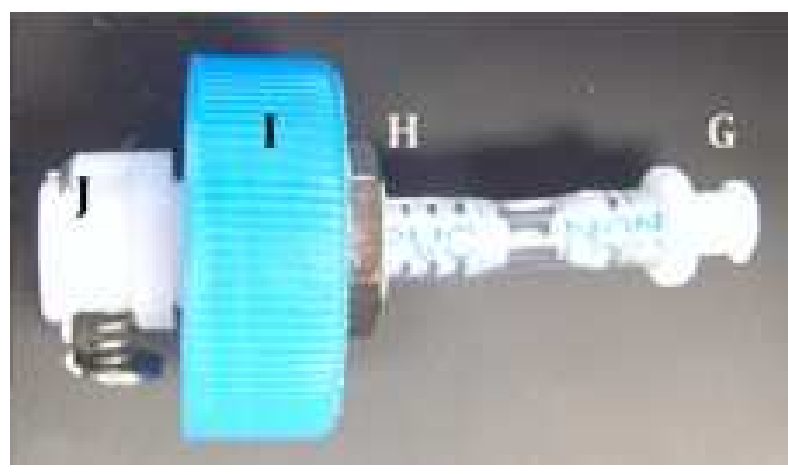

Figure 4.2 Part A detail

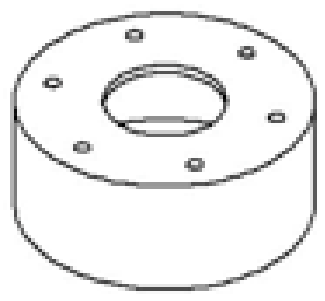

Figure 4.3 Part I detail

- $\quad$ Piece A: Lid apparatus (closer image in Figures 4.2 and 4.3)

○ Piece G: A syringe filled with cells (discussed later in cell seeding) hooks onto this and injects cells through the tubing and gelatin tube. This is also 
where fluid is injected to wash out the product from the mammary cells, once lactation is initiated.

○ Piece H: The nut allows for the valve $(\mathbf{J})$ to be screwed tightly in place with the gelatin tube attached.

○ Piece I: The lid holds the valve (J) and has small holes for gas exchange (Figure 4.3).

- Piece J: One of the valves the gelatin tube clicks into. This part can be moved up and down with use of the nut to ensure proper fit of the gelatin tube in the bioreactor.

- Piece B: Media input valve with cap

- Piece C: Gelatin tube and media storage space

- Piece D: Media output valve with cap

- Piece E: IV clamp used during the cell seeding process

- Piece F: Tubing and valve through which cell products will be obtained Once the bioreactor is assembled and sterilized, it is ready for cell seeding. The initial assembly and sterilization protocols are found in Appendix A.

The next step is to aseptically prepare the bioreactor for seeding the cells. This includes attaching the treated gelatin tubes and placing the bioreactor in a rack of others. From this point onward, all procedures are done in the sterile hood with sterile gloves and extreme caution is taken to keep everything sterile. The gelatin tube is secured into the bioreactor with forceps, and the tubing (piece F) is pulled putting the gelatin tube in position for the lid. The lid can now be screwed on, making sure to use the nut for proper gelatin tube placement (Figure 4.4 depicts this process). The bioreactor is placed in the 
rack and the other bioreactors are to be prepared in the same manner. The bioreactors are now ready for cell seeding, which should be done immediately following the assembly.
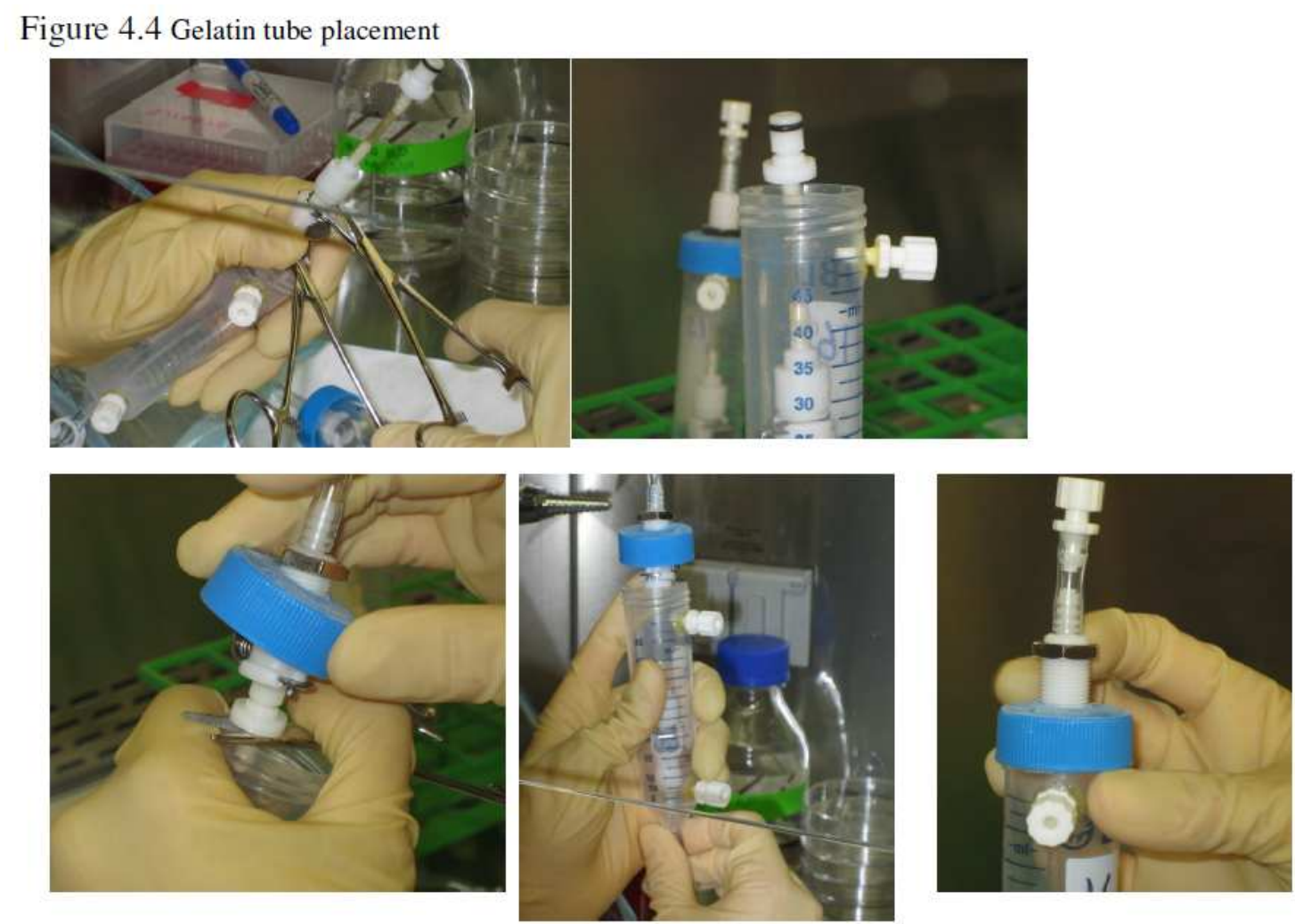

Cell seeding starts with the assembled bioreactor. Mammary cells that have been grown to confluence are used. Cells are separated from the plastic using trypsin and are placed in warmed cell growth media. A small sample is taken to count the cells and a $3 \mathrm{~mL}$ sterile syringe (with needle removed) is filled with cells, screwed on to Piece $\mathrm{G}$ and the plunger is pushed until cells reach the bottom of the gelatin tube. Once the fluid reaches this point, the IV clamp (Piece E) is clipped shut so the cells will stay near the gelatin to grow. Warmed growth media is put into a $50 \mathrm{~mL}$ syringe that is then attached to Piece B and injected into the bioreactor. The process is repeated for the other bioreactors. The cells need to be seeded in the bioreactors quickly so no attachment or 


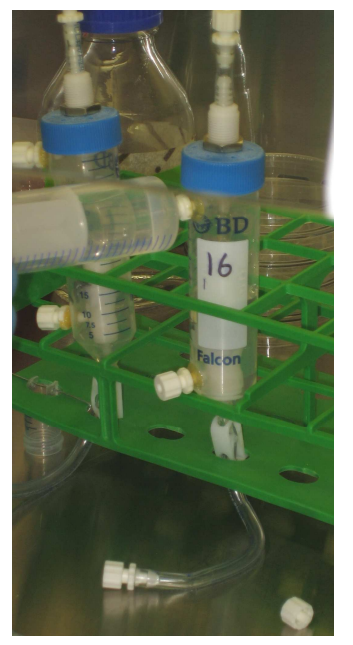

cell death occurs in the falcon tube. The bioreactors are placed into the incubator at $37^{\circ} \mathrm{C}$. Media is changed every 3-4 days by draining the media from Piece D and fresh media is injected with a $50 \mathrm{~mL}$ syringe in Piece B (Figure 4.5). The bioreactors are initially used to test for confluence. The next step would be switching the media from the growth media to a lactation media and then measuring the output of the mammary cells.

Figure 4.5 Media exchange

\section{RESULTS AND DISCUSSION}

The cell seeding results show that some growth is possible in the bioreactor. Problems occurred with the bioreactors leaking causing results to be lost. Figure 4.6 demonstrates what mammary cells look like when grown to confluence on regular cell growth plates (Petri dishes). The cells cover the plate until there are no open spaces.
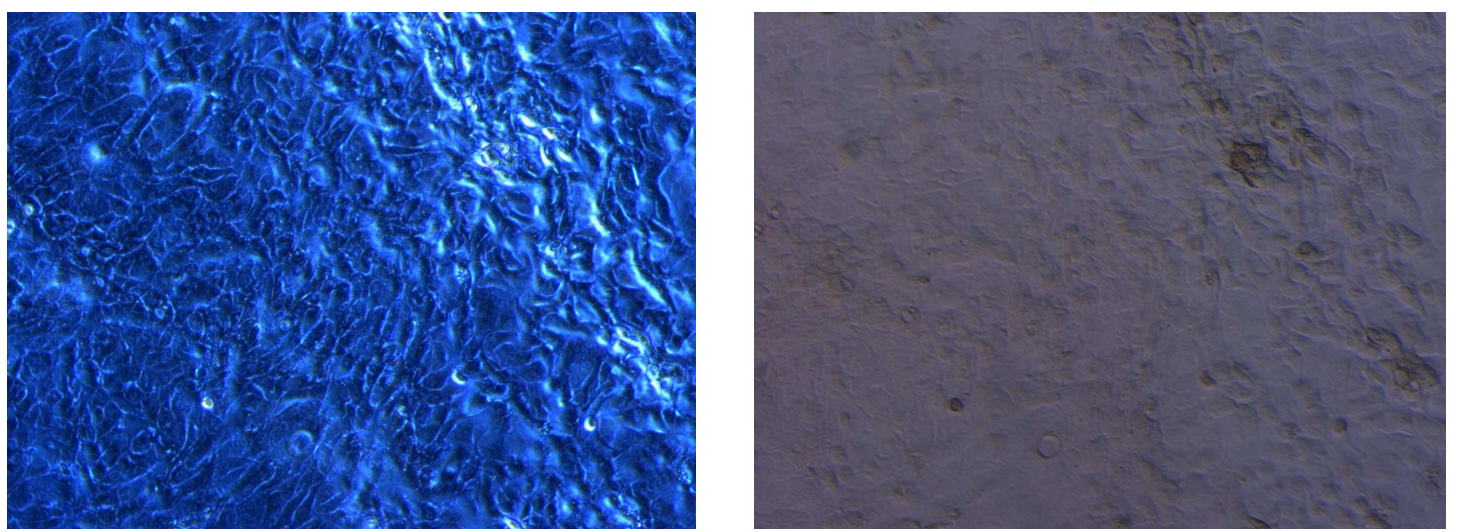

Figure 4.6 Two views of mammary cell growth on Petri dishes

Previous work has shown mammary cells grow just as easily on the treated gelatin as on the Petri dishes. Introduction of different geometry might have been what caused difficulties in the growth of the mammary cells. Only some parts of the gelatin tubes 
seemed to have growth. Figure 4.7 shows two of the pictures of the treated gelatin tubes cut open two days after mammary cells were implanted in the bioreactor.
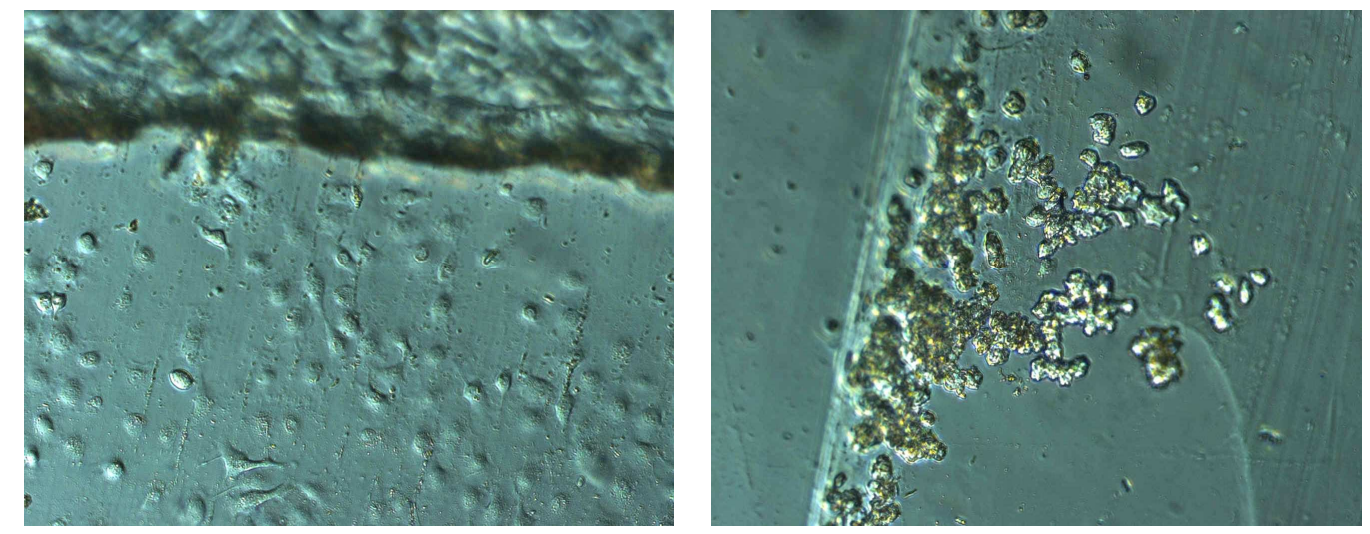

Figure 4.7 Mammary cell growth on treated gelatin tubes 2 days after implantation The next pictures show more gelatin tubes cut open a week after the cells were implanted.

Figure 4.8 Mammary cell growth on treated gelatin tubes one week after implantation
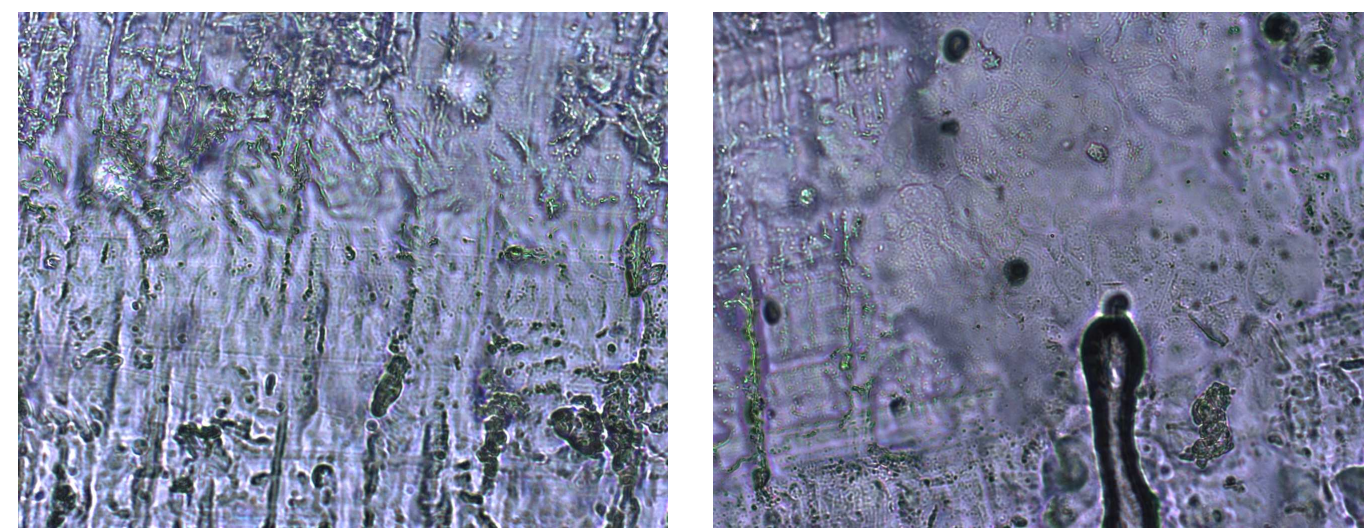

The only presence of anything on the gelatin was seen in Figure 4.8 - possibly cells, but not likely. The gelatin tubes that were examined at this point all looked similar with no growth.

There could be many reasons the tubes did not show mammary cell growth. The first reason could have been a small leak in the gelatin tube. A small leak may not have been noticed and the cells could have gone into the media. Another possible reason was that the cells settled in the valve at the bottom of the gelatin tube because of gravity. If the cells did not get the nutrients they needed, which would be likely if they were in the 
valve, cell death would be inevitable. Other possible reasons for lack of cell growth could have been the amount of cells implanted, the gelatin wasn't porous enough, the toxicity of bioreactor sealant, or a bacterial infection. 


\section{Chapter 5: CONCLUSION}

The research completed shows potential in the three-dimensional polarized environment for the mammary cells. The concept of the mammary cell and bioreactor system has the ability to be a great asset to the biopharmaceutical industry. Transgenic animals, another alternative, are expensive and have proven to be difficult to gain consistent results from. This system provides a much more affordable and reliable solution to transgenic animals.

The genomic and proteomic research for using mammary glands as protein production tools is far-reaching. A full-scale system has production potential and even has the possibility of going into other fields of biotechnology like tissue engineering. This system may also help with current research of bioreactors, secretion systems, and living system production. This mimicked living system provides the ability to manufacture biopharmaceuticals in a factory-like setting. Working with mammary cells and creating an artificial environment for them to survive, which was the goal of this project, can aid in the production of complex compounds. 


\section{Chapter 6: FUTURE WORK}

Extensive work has optimized the bioreactor environment for the gelatin tube and mammary cell growth. The ultimate goal of this project is for the mammary cells to secrete in the bioreactors as they would in vivo. Previous work is promising and provides confidence in moving on with this project. Many more sets of bioreactors and gelatin tubes need to be assembled and injected with cells.

A highly concentrated solution of cells would provide a better chance of adhesion to the gelatin. Once the cells are thriving, the gelatin tube can be flushed with phosphate buffered saline (PBS) to further induce the polarization needed for the bioreactor system. The polarization is vital in the secretion process because the PBS will be collecting the results and the cells will have the nutrients to sustain life only on the basal side (outside of tube).

The next step in the process would be to switch from growth media to lactation media, inducing secretion. The mammary cells should start producing milk, which can then be measured by testing for the presence of lipids. Lipid production may be difficult to measure because of the relatively small amount that the cells secrete, so running the PBS through the bioreactor system multiple times should increase the concentration. The production from the bioreactor should be compared to the production of the cells in a similar sized gelatin environment to see if there is a drastic difference in production. If little growth continues to occur, toxicity tests should be done on the glue used on the seals of the bioreactor. 


\section{REFERENCES}

1. Adams, Josephine C., Fiona M. Watt. Regulation of development and differentiation by the extracellular matrix. Development 1993; 117: 1183-1198.

2. Ahmed, M. Rafiuddin, U. Vankateshwarlu, R. Jayakumar. Multilayer peptide incorporated collagen tubules for peripheral nerve repair. Biomaterials 2004; 25: $2585-2594$.

3. Alberts, Bruce, Alexander Johnson, Julian Lewis, Martin Raff, Keith Roberts, Peter Walter. Molecular Biology of the Cell, $4^{\text {th }}$ Edition. Garland Science, New York. 2002.

4. Asenjo, Juan A. (ed.), Jose C. Merchuk (ed.). Bioreactor System Design. Marcel Dekker, New York, NY. 1995.

5. Barcellos-Hoff, M.H., J. Aggeler, T.G. Ram, M.J. Bissell. Functional differentiation and alveolar morphogenesis of primary mammary cultures on reconstituted basement membrane. Development 1989; 105: 223-235.

6. Cartwright, Terence. Animal Cells as Bioreactors. Cambridge University Press, Cambridge, New York. 1994. 
7. Hurley, Walter L. Milk Composition and Synthesis. Retrieved from http://classes.ansci.illinios.edu/ansc438/milkcompsynth/milkcompsynthresources. html. Copyright 2009.

8. Jayakrishnan, A., S.R. Jameela. Glutaraldehyde as a fixative in bioprostheses and drug delivery matrices. Biomaterials 1996; 17:471-484.

9. Kozlov, P.V., G.I. Burdygina. The Structure and Properties of Solid Gelatin and the Principles of their Modification. Retrieved from http://albumen.conservationus.org/library/c20/kozlov1983.html. Copyright 1991.

10. Lee, Sang Bong, Yong Hankim, Moo Sang Chong, Seung Hwa Hong, Young Moo Less. Study of gelatin-containing artificial skin V: fabrication of gelatin scaffolds using a salt leaching method. Biomaterials 2005; 26:1961-1968.

11. Muschler, George F., Chizu Nakamoto, Linda G. Griffith. Engineering Principles of Clinical Cell-Based Tissue Engineering. The Journal of Bone and Joint Surgery 2004; 86-A: 1541-1558.

12. Mustafa, Dr. Arif. Anatomy of the Mammary Gland. Retrieved from http://animsci.agrenv.mcgill.ca/courses/460/. Copyright 2001. 
13. Sachlos, E., J.T. Czernuszka. Making tissue engineering scaffolds work. Review on the application of solid freedom fabrication technology to the production of tissue engineering scaffolds. European Cells and Materials 2003; 5:29-40.

14. Sachlos, E., N. Reis, C. Ainsley, B. Derby, J.T. Czernuszka. Novel collagen scaffolds with predefined internal morphology made by solid freeform fabrication. Biomaterials 2003; 24:1487-1497.

15. Shuler, Michael L., Fikret Kargi. Bioprocess Engineering. Prentice Hall PTR, Upper Saddle River, NJ. 2002.

16. Singh, Harmeet, Eng Seng Ang, T.T. Lim, Dietmar W. Hutmacher. Flow Modeling in a Novel Non-Perfusion Conical Bioreactor. Biotechnology and Bioengineering 2007; 97: 1291-1299.

17. von Endt, David W., Mary T. Baker. The Chemistry of Filled Animal Glue Systems. Retrieved from http://albumen.conservation-us.org/library/c20/vonendt1991.html. Copyright 1991.

18. Yung, C.W., L.Q. Wu, J.A. Tullman, G.F. Payne, W.E. Bentley, T.A. Barbari. Transglutaminase crosslinked gelatin as a tissue engineering scaffold. Journal of Biomedical Materials Research Part A 2007; 83A:1039-1046. 


\section{APPENDICES}

Appendix A: Protocols

Protocol for Mixing and Casting/Taping Gelatin Sheets ....................................35

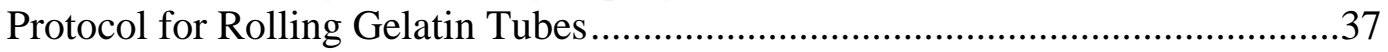

Protocol for Glutaraldehyde Treatment of Gelatin Tubes ...................................38

Protocol for Initial Bioreactor Assembly .........................................................40

Protocol for Bioreactor Sterilization ..........................................................45

Protocol for Assembling Bioreactor in Preparation of Cell Seeding ....................47

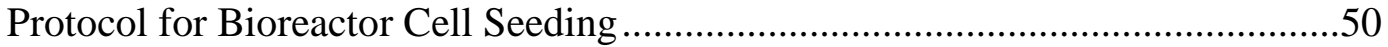

Protocol for Bioreactor Media Preparation ....................................................52

Protocol for Plating, Splitting/Passaging, and Freezing of Cells .........................54

Protocol for Cell Media Preparation ..............................................................56

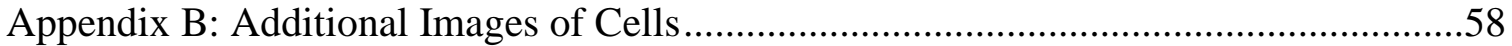




\section{Appendix A: Protocols}




\section{Protocol for Mixing, Casting/Taping Gelatin Sheets}

***Casted films last approximately 2 weeks.

\section{Materials:}

Masking tape (Staples brand)

Autoclaved Plastic casting blocks/plates

300 Bloom Type A Gelatin (Sigma G1890-500g)

Sterile (autoclaved) Milli Q water

Sterile (autoclaved) pipettor

Sterile pipette tips

\section{Method:}

All steps (except 2-4) must be done inside the sterile hood.

**Make sure to ethanol your gloves and wipe down the hood, as well as wipe off anything to be put in the hood with a Kimwipe soaked in ethanol, every time you enter the hood.

1. Using masking tape (that has been opened and kept inside the hood), mask off segments on a sterilized autoclaved plastic plate. Tape top and bottom of segments first using 2 layers of tape. Then tap the sides of the segments using 2 layers of tape (This is easier to remove once films are dry). Once finished taping, label each casting block with what gelatin concentration you are casting, your initials and date.

$\underline{\text { Sizes: }}$

Films for diffusions $-30 \mathrm{~mm}$ x $30 \mathrm{~mm}$, use $1 \mathrm{~mL}$ of gelatin solution for casting per square

Tubes $-40 \mathrm{~mm} \times 18 \mathrm{~mm}$, use $0.8 \mathrm{~mL}$ of gelatin solution for casting per rectangle

Calculations for amount to pipette:

$$
\text { Baseline } \rightarrow \frac{900 \mathrm{~mm}^{2}}{1 \mathrm{~mL}}=\frac{\text { area of section (in } \mathrm{mm}^{2} \text { ) }}{\text { new volume }}
$$

2. Heat $10 \mathrm{~mL}^{* *}$ of sterile Milli $\mathrm{Q}$ water in autoclaved $30 \mathrm{~mL}$ beaker to at least 60 degrees Celsius, cover with Kimwipe while heating to reduce contamination. Reduce heat to prevent boiling.

3. Add appropriate measurements of gelatin** using sterile scoop:

$\rightarrow$ For $5 \%$ gelatin solution, add $.5 \mathrm{~g} 300$ Bloom Type A gelatin* to $10 \mathrm{~mL}$ of heated sterile Milli Q water.

$\rightarrow$ For $7 \%$ gelatin solution, add .7g 300 Bloom Type A gelatin* to $10 \mathrm{~mL}$ of heated sterile Milli Q water.

* cover with Kimwipe until ready to put into solution

** adjust amount of gelatin/water per need

4. Stir until solution is homogeneous, using a stir bar, and move into the hood (use ethanol soaked Kimwipe to wipe outside of beaker, DO NOT spray beaker).

5. Using sterile pipette tips without filters, pipette the appropriate amount of gelatin solution into each area.

6. When pipetting out the solution:

- Cast one section at a time, gelatin can dry out and solidify quickly.

- When sucking up the gelatin solution, make sure you only push down to the first stop on the plunger. 
- When dispensing, make sure to not push down on the plunger after the first stop point (even if you have a small amount of solution left) or else you will create bubbles in your film on your casting block.

- Gently spread your film along the edges of the masking tape. You do not need to use a lot, just ensure the gelatin will have something to stick to while it is drying.

- Try to move bubbles out of the casted area and on the masking tape so there is a smooth surface. Use a new pipette tip if you need to suck off bubbles.

- Pipette solution as evenly as possible over section so that it will be less likely to tear when removing (once dry).

- Use a new non-filtered pipette tip for each casted segment.

7. Let dry overnight in hood.

8. Carefully remove the gelatin sheets from the plate by removing most of the tape.

Tweezers may be used as an aid. Concentrate on removing one film at a time and be careful not to tear films. Keep trash tape in hood until completely finished with removing all films to minimize going in and out of the hood.

9. Place the sheets in a sterile Petri dish and label with:

Your initials

The date

Sheet size

Gelatin concentration

10. Remove the casting block from the hood and remove any tape residue from the plate.

11. Wash all lab supplies with Alconox and water. Dry completely before autoclaving. 


\section{Protocol for Rolling Gelatin Tubes}

Materials:

Petri Dish

Sterile Autoclaved Milli Q water

Teflon rod

Valve pieces

Method:

All steps must be done inside the sterile hood.

*** Make sure to ethanol your gloves and wipe down anything you put inside the hood with a Kimwipe soaked in ethanol.

12. Pour sterile Milli Q water into a sterile Petri dish, until about $2 / 3$ full.

13. Assemble rod and valve apparatus (as seen below) and set aside.

14. Place dehydrated gelatin film in the sterile Milli Q water for a few seconds to rehydrate (make sure to saturate whole sheet).

15. Using sterile forceps and/or sterile gloves, gently remove the film from the water and carefully wrap it around the Teflon mandrel and valve apparatus.

**The film will be very fragile until it is treated with glutaraldehyde, so be careful.

16. Make sure to align the end of the films to edge of the grooved sections closest to the valve. You may need to adjust the distance of the valve pieces to accommodate the length of the gelatin film.

17. Wrap the film tightly and neatly around the mandrel/rod in order to eliminate any air bubbles. Try to avoid too much overlap and wrinkles in the tube. Try to keep the $\mathrm{rod} / \mathrm{valve}$ apparatus as dry as possible, doing that will aid in the sheet sticking easier.

18. You may need to keep your glove tips moistened to prevent your gloves from sticking to the sheet.

19. If film tears or rips, dispose of the gelatin film and start process over with a new film and Teflon apparatus.

20. When tube rolling is complete, let the tube dry completely (in sterile Falcon tube or on autoclaved plastic casting block) before starting the glutaraldehyde treatment process.

21. Make sure to label tube or plate(w/ tape) with:

Your initials

The date

Gelatin \%

Untreated

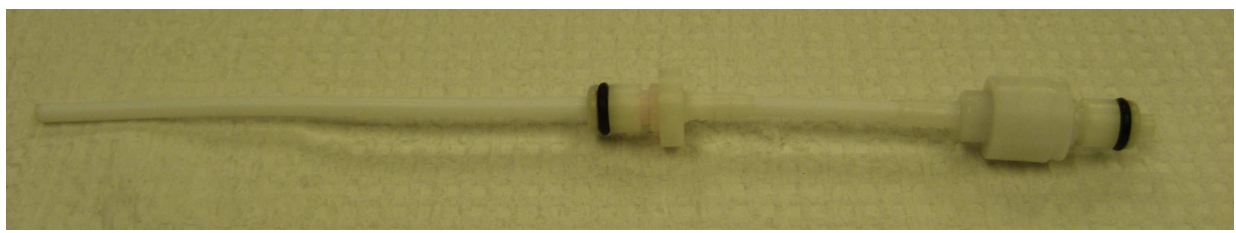




\section{Protocol for Glutaraldehyde Treatment of Gelatin Tubes}

*** Lab coat and gloves required for entire treatment process!!!

Wear closed toed shoes and pants.

\section{Materials:}

25\% Glutaraldehyde (Sigma G6257-100mL)

Glycine (Sigma G8790-100mg)

Sterile Milli Q water

Petri dishes

Sterile Serological Pipettes

Agitator

Aspirator

Sterile, Autoclaved Media Bottles

Stock Solution Prep: (Mixing should occur in sterile hood)

1. Prepare a solution of $1 \%$ Glycine in a sterile autoclaved $250 \mathrm{~mL}$ media bottle.

2. Measure 1g of Glycine in a weigh boat. Place in hood and add to sterile media bottle.

3. Add $100 \mathrm{~mL}$ of PBS using sterile serological pipette to media bottle, pipette up and down to mix.

4. Prepare a $2.5 \%$ solution of Glutaraldehyde in a sterile autoclaved $250 \mathrm{~mL}$ media bottle.

5. Use sterile $25 \mathrm{~mL}$ serological pipette to add $25 \mathrm{~mL}$ of $25 \%$ Glutaraldehyde to sterile media bottle. Dispose of pipette.

6. Use a new sterile serological pipette to add $225 \mathrm{~mL}$ of sterile Milli Q water to media bottle. Pipette up and down to mix.

Method: (Entire treatment occurs in sterile hood)

***Ethanol your gloves and wipe down hood with ethanol before introducing anything into hood. Wipe down anything that you put in the hood with a Kimwipe soaked in ethanol.

22. Once rolled tubes are dry, place in a sterile $15 \mathrm{~mL}$ Falcon tube.

23. Place 1 autoclaved $250 \mathrm{~mL}$ beaker in hood and label $0.1 \%$ (or $0.3 \%$ ) Glutaraldehyde with tape.

24. Prepare $120 \mathrm{~mL}$ solution of $0.1 \%$ (or $0.3 \%$ ) Glutaraldehyde for treatment of 10 tubes.

25. Using a sterile $5 \mathrm{~mL}$ serological pipette, add $4.8 \mathrm{~mL}$ (or $14.4 \mathrm{~mL}$ for $0.3 \%$ ) of $2.5 \%$ Glutaraldehyde to beaker. Dispose of pipette.

26. Add $95.2 \mathrm{~mL}$ (or $105.6 \mathrm{~mL}$ for $0.3 \%$ ) of sterile Milli Q water to beaker with a sterile $25 \mathrm{~mL}$ serological pipette. Once all water is added, pipette solution in beaker up and down to mix. Dispose of pipette.

27. Add $11-12 \mathrm{~mL}$ of $0.1 \%$ (or $0.3 \%$ ) Glutaraldehyde to each falcon tube with a sterile $10 \mathrm{~mL}$ serological pipette (add enough to completely cover gelatin tube and top valve). To ensure adequate crosslinking, leave the glutaraldehyde in the Falcon tube for 20 minutes.

28. Fill 3 autoclaved $50 \mathrm{~mL}$ graduated cylanders with Milli $\mathrm{Q}$ water.

29. Aspirate glutaraldehyde and dip into three vials of water in succession to rinse the teflon parts and tube. After every 3 gelatin tubes, dump water and fill with fresh sterile Milli Q water.

30. Fill Falcon tubes with sterile Milli Q water using a sterile $25 \mathrm{~mL}$ serological pipette. Put enough water to completely cover gelatin tube and top valve. Dispose of pipette. 
Once all of the Falcon tubes have water in them, tape entire Falcon tube holder to pipettor battery to agitate all 10 tubes at the same time.

31. Leave to rinse under agitation for 3 hours.

32. Aspirate off the water and fill falcon tubes with $1 \%$ Glycine using a sterile $25 \mathrm{~mL}$ serological pipette. Dispose of pipette. Once all of the Falcon tubes have water in them, tape entire Falcon tube holder to pipettor battery to agitate all 10 tubes at the same time.

33. Leave to rinse under agitation for $\mathbf{2}$ hours.

34. Aspirate off the Glycine and fill Falcon tubes with sterile Milli Q water with a sterile $25 \mathrm{~mL}$ serological pipette. Dispose of pipette once all tubes are completed. Once all of the Falcon tubes have water in them, tape entire Falcon tube holder to pipettor battery to agitate all 10 tubes at the same time.

35. Leave to rinse under agitation for $\mathbf{1}$ hour.

36. Repeat steps 13 and 14 twice with fresh sterile Milli $\mathrm{Q} \mathrm{H}_{2} \mathrm{O}$. (Tubes should rinse for a total of 3 hours in sterile Milli Q water).

37. After the final treatment step, let the tubes dry completely in the hood before removing the Teflon mandrel/rod. To do this, remove tubes from falcon tube and place on an autoclaved block (the ones used for making the gelatin sheets).

38. Once dry (12-24 hours), remove Teflon rod carefully. Place completed gelatin tubes in a sterile bag.

39. Make sure to label the bag $0.1 \%$ (or $0.3 \%$ ) GA in addition to the concentration of gelatin, initials and date. 


\section{Protocol for Initial Bioreactor Assembly}

*** Done outside of sterile hood

\section{Parts List:}

$1-50 \mathrm{~mL}$ Falcon Tube

4-1/8" ID to Male Luer Lock Converters

4-Female Luer Lock Caps

1-1/8" ID Valved Snap Lock Assembly

1-1/8" ID Non-Valved Snap Lock Assembly (including nut)

$1-1 / 4$ " OD Tube Clamp

7"-1/8" ID PVC tubing

Quick Setting Gel Epoxy (Temperature use range of up to 300 degrees F)

\section{Tools List:}

Power Drill with 1/2", 1/4", 1/8", 1/16" bits

Razor Blade

Sand Paper

Ruler

Nitrile Gloves

Permanent Marker

Autoclave

\section{Procedure:}

1) Using a 1/8" bit on the power drill, drill two holes in the Falcon Tube body in the locations indicated on the drawing below. Take care not to drill the opposite side of the tube when the bit pierces the wall. Sand all rough edges and surfaces bordering the holes.

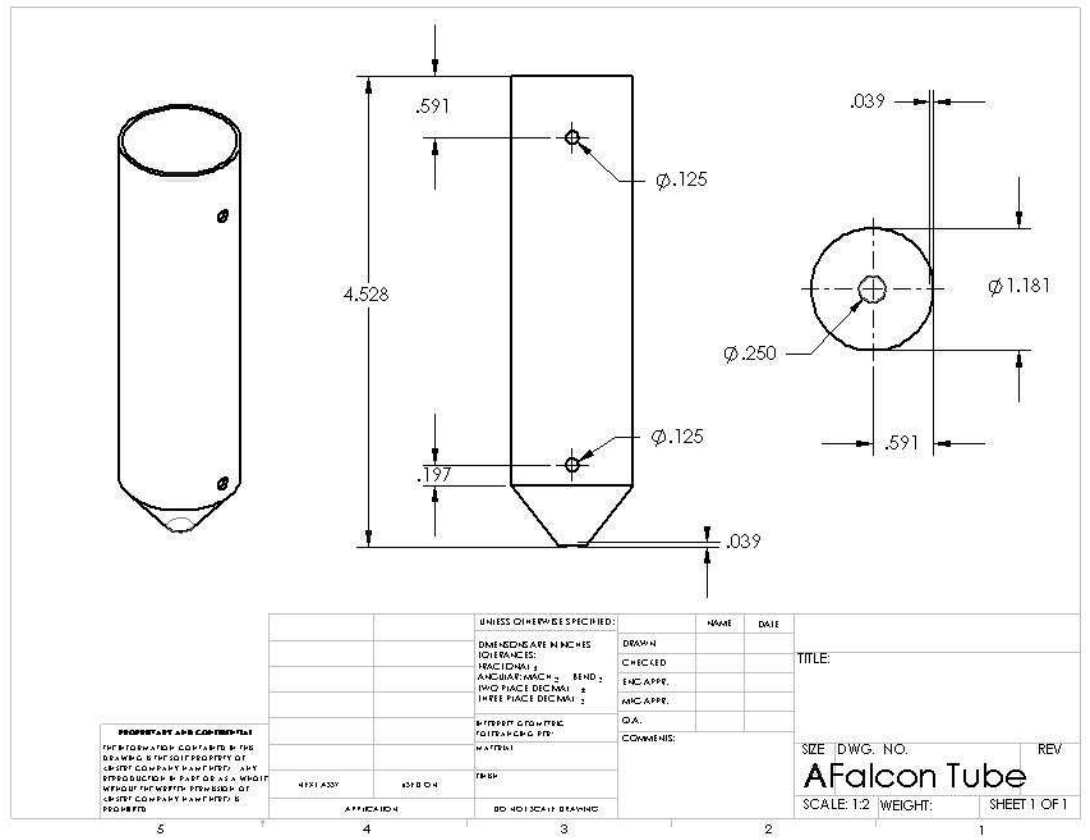

2) Using a 1/4" bit, drill a hole at the tip of the conical section of the Falcon Tube as indicated in the drawing above. 
3) Remove the lid from the Falcon Tube and drill 1 hole in the center of the lid using the $1 / 2$ " bit. (See the drawing below for hole location.) Sand all rough edges.

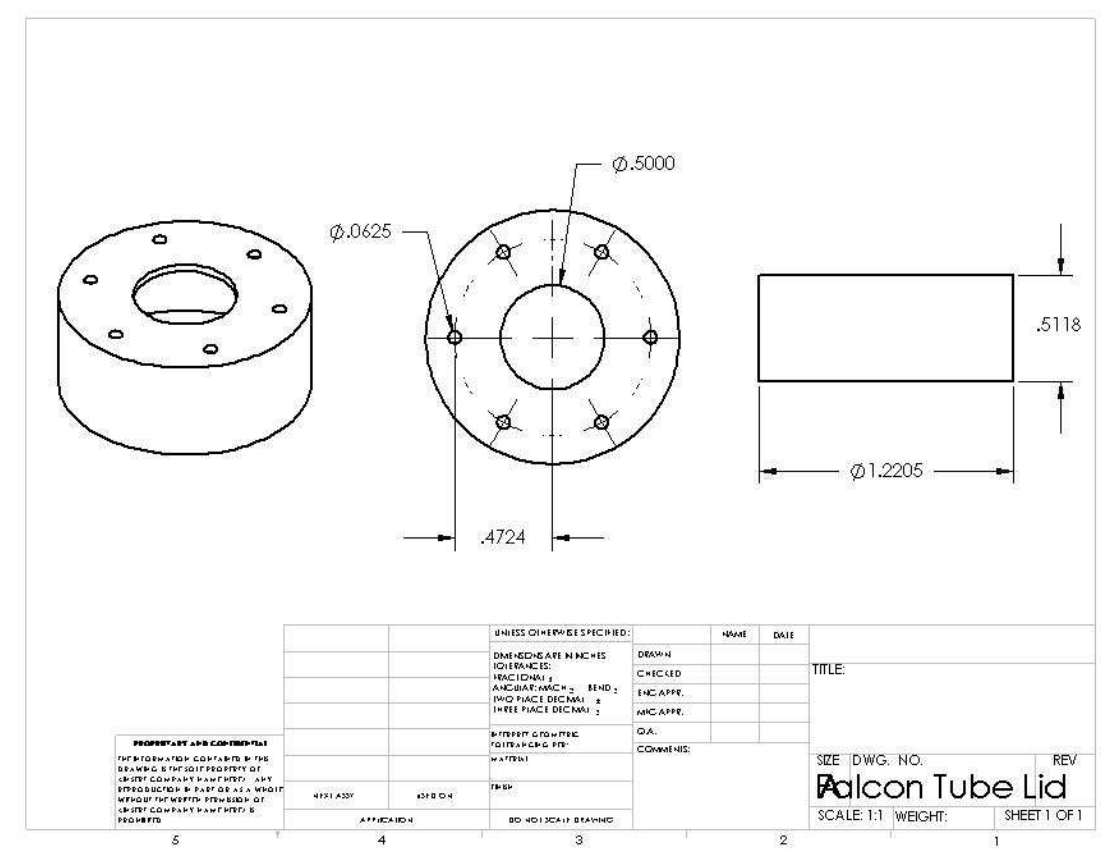

4) Using the 1/16" bit on the power drill, drill 6 holes in the lid in the locations indicated on the drawing provided. Sand all rough edges. Set the Falcon Tube and lid aside.

5) Measure out and use the razor blade to cut a 6" segment and a 1" segment of PVC tubing and set aside.

6) Take two 1/8" ID to male luer lock converters and roughen all surfaces on the barbed end with sand paper (see picture below.)

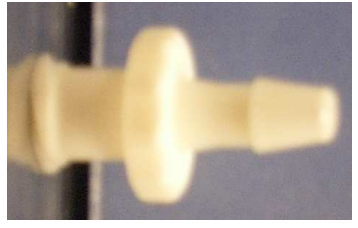

7) Take the valved snap lock assembly and use a razor blade to remove the plastic surrounding the lock release until the plastic is flush with the natural curve of the component (see picture below.)

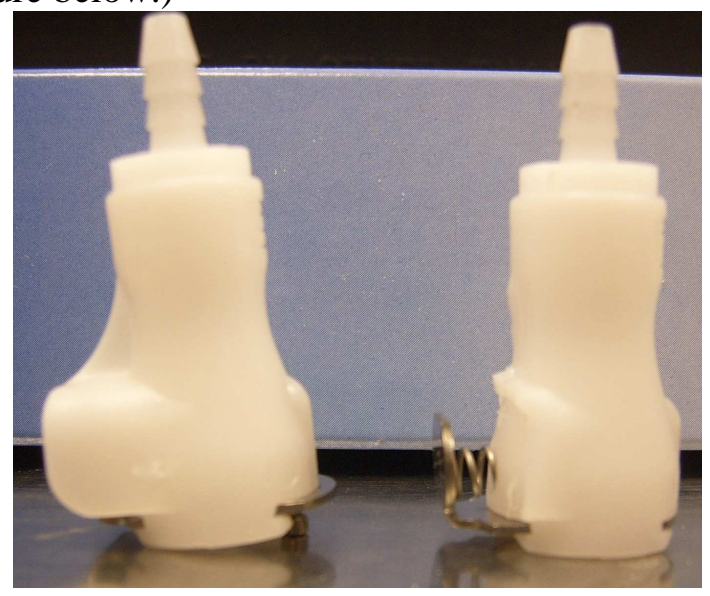


8) Insert the 6" segment of tubing into the hole at the tip of the conical section of the Falcon Tube and feed this tubing as far as possible without pulling the tubing out of the hole.

9) Insert a valved snap lock assembly into the end of the tubing that was fed into the Falcon Tube (see picture below.)

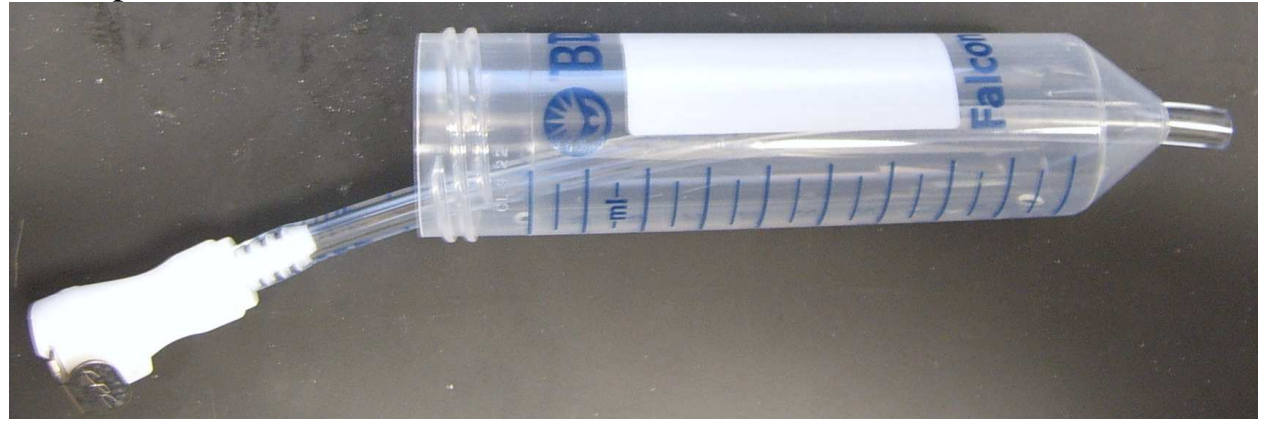

10) Run the opposite end of the 6" segment of tubing through a tube clamp so that the locking mechanism faces toward the tip of the conical section of the Falcon Tube (see picture below.)

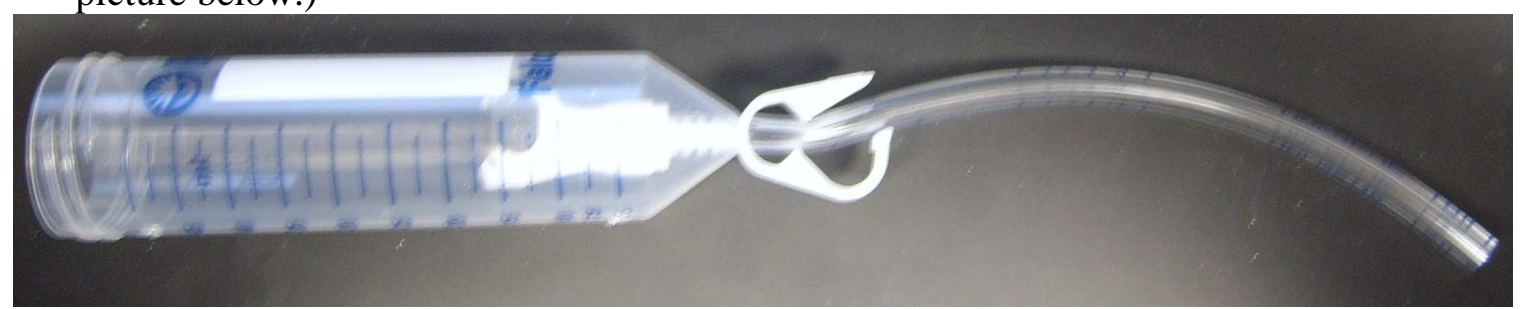

11) Insert a 1/8" ID to male luer lock converter into the open end of the 6" segment of tubing.

12) Wear nitrile gloves and cover the work space with aluminum foil. Then, mix a small amount of the gel epoxy in weigh boat or other appropriate container.

13) (CAUTION: this step must be done quickly and carefully. Epoxy hardens in 5 min and becomes extremely hot in the process. DO NOT TOUCH WITH BARE HANDS) apply a small amount of epoxy to the barbed end of each 1/8" ID to male luer lock converter and immediately force fit the converter into the two remaining $1 / 8$ " holes on the Falcon Tube taking care not to obstruct the path of flow through the converter with epoxy (see picture below.) Set aside to dry for 1 hour.

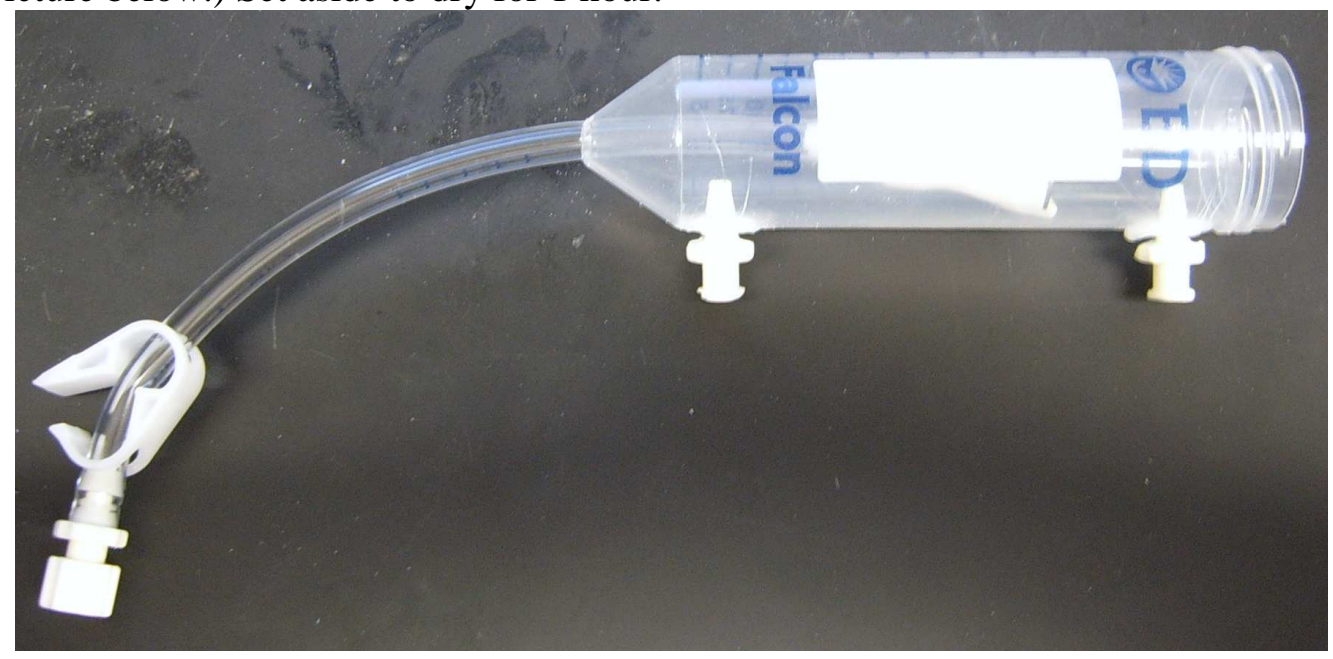


14) Take the remaining 1 " segment of tubing and place a $1 / 8$ " ID to male luer lock converter in one end and the non-valved snap lock assembly in the other end (see picture below.)

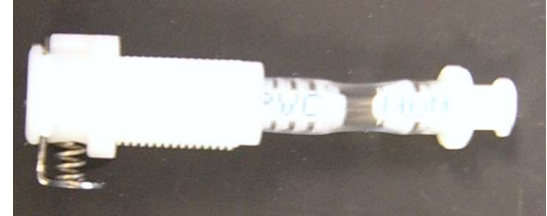

15) Remove the nut from the snap lock assembly and insert the threaded end of the snap lock assembly through the 1/2" hole in the Falcon Tube lid such that the tubing is on top of the lid. Replace the nut and screw on just enough for it to remain on the threading (see picture below.)

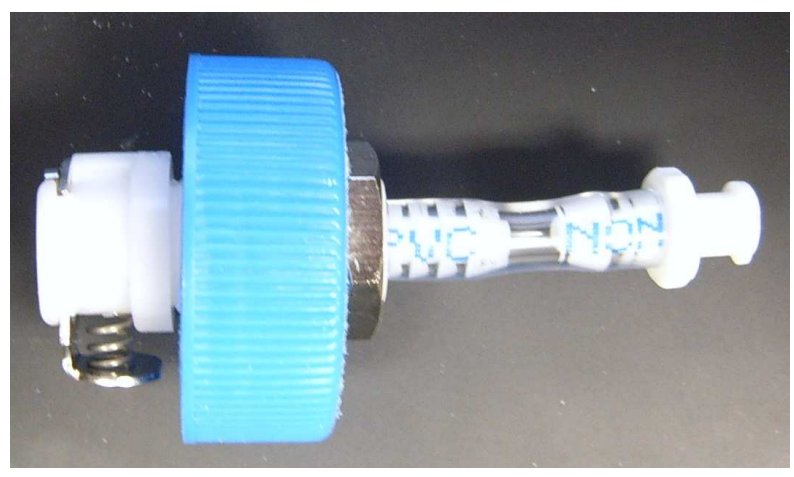

The following steps are only to be performed after the epoxy has been allowed to dry for at least one hour

16) Remove the 2 male components of the 2 snap locks by pressing the button on the side of each snap lock assembly. Set the male component aside for use in gelatin tube casting.

17) Attach 4 female luer lock caps to all 4 exposed male luer lock fittings.

18) Rinse all parts with Alconox and Milli $Q$ water. Allow to dry completely.

19) Arrange the bioreactor as shown below. Be sure to feed the 6" tubing segment as far into the Falcon Tube as the lid will allow. Also, ensure that both of the snap clips are engaged (button pressed in and locked in the open position) and that the tube clamp is open.

Finally, check that the nut on the lid assembly is as high as possible on the threading (see picture below.)

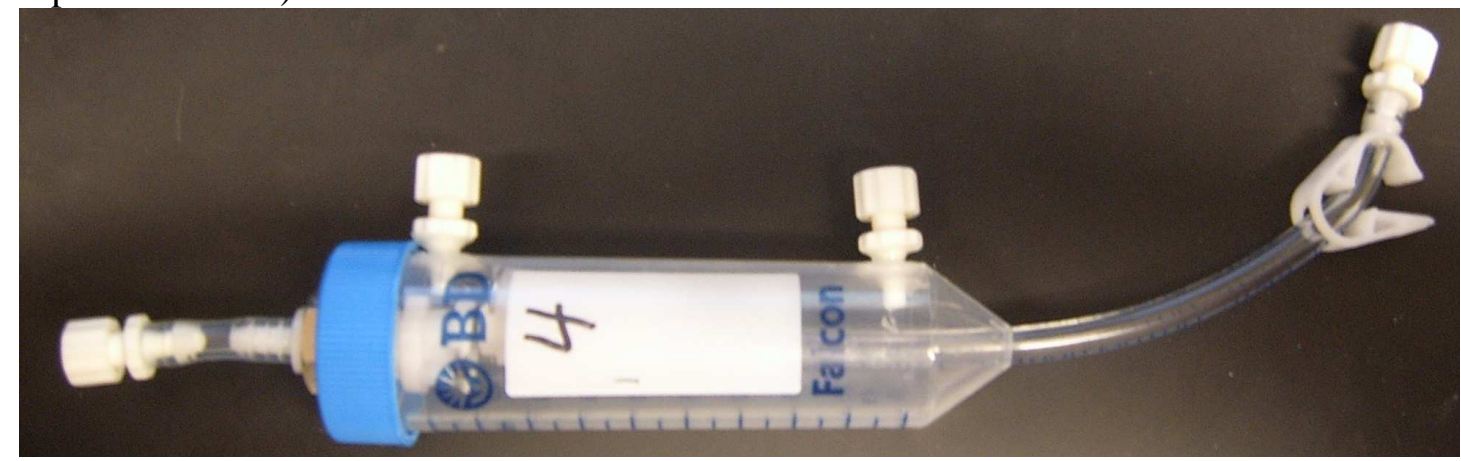

20) Using a permanent marker place a tick mark on the white field of the Falcon Tube body to indicate that this bioreactor has undergone a sterilization cycle. 
The following steps are only to be performed after the epoxy has been allowed to completely cure for 24 hours

21) Autoclave the pouch according to the parameters outlined in the Bioreactor Sterilization Protocol.

22) Repeat steps 1-21 for each bioreactor 


\section{Protocol for Bioreactor Sterilization}

Preparation

1. Wash bioreactor assembly with water and alconox and allow to air dry. Then rinse with MilliQ water and allow to air dry again.

2. Ensure that the autoclave has enough water in it and that weekly maintenance has been performed as scheduled.

\section{Procedure}

1. Ensure that the natural curvature of the tubing and the tube clamp are in the same plane as the two outside ports of the bioreactor body to avoid any unnecessary stress on the tubing and/or the two outside ports.

2. Place two bioreactors in a sterilization pouch so that they are touching as little as possible. (See picture below.) Remove the adhesive strip and close the bag, ensuring a complete seal.

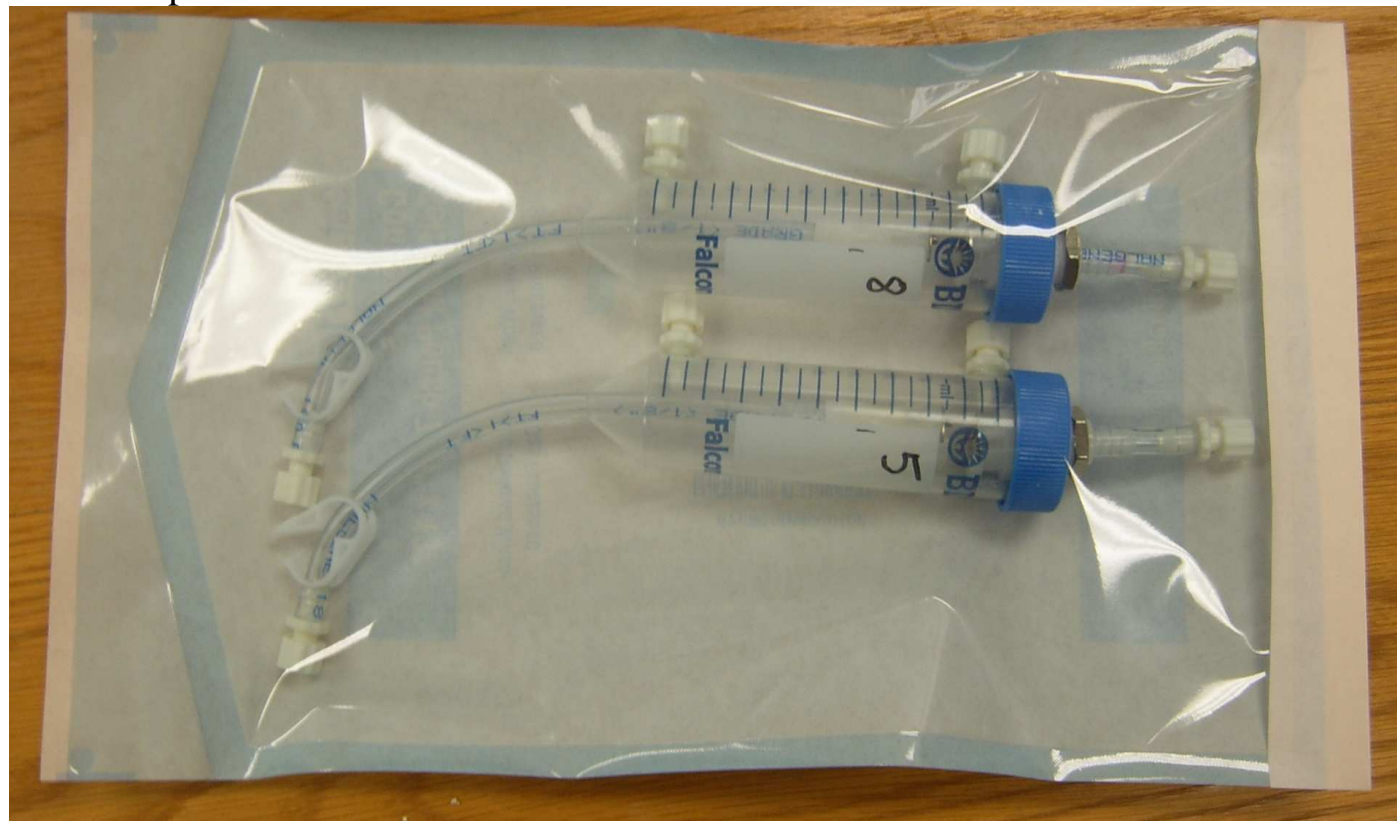

3. Place the sterilization pouch on an autoclave tray with the clear blue side facing up. Place a maximum of two trays in the autoclave such that the clear blue side of the sterilization pouches is not allowed to touch any metal surfaces.

4. Close and lock the autoclave.

5. Press the button marked " 1 " and ensure that the display reads the following parameters:

- Temperature: $250^{\circ} \mathrm{F} / 121^{\circ} \mathrm{C}$

- Pressure: $15 \mathrm{psi} / 104 \mathrm{kPa}$

- Duration: 15 min

- Dry Method: Fast Vent

- Dry Time: 30 min

6. Press start. The autoclave will heat up, perform the programmed cycle, then automatically open slightly for the 30 min dry time. Do not remove the pouches until this dry time has completed. 
7. After the 30 min dry time has completed, open the autoclave door and remove the pouches

8. Allow the pouches to sit, clear blue side facing up, for a minimum of 1 hour and 30 min before attempting to use the bioreactors for any application. 


\section{Protocol for Assembling Bioreactor in Preparation of Cell Seeding}

Preparation

1. Ensure all components, tools, and materials have been autoclaved in sterilization pouches.

2. Clean assembly area in the sterile hood with ethanol.

3. Wipe down all sterilization pouches and other material packaging with ethanol.

4. Place bioreactors, gelatin tubes, falcon tube $\operatorname{rack}(\mathrm{s})$, forceps, and sterile gloves in the sterile hood.

Assembly (requires 2 people-denoted (1) \& (2))

1. (1) \& (2)-Open a pair of appropriately sized sterile gloves taking care not to touch the inside of the packaging or the outside of the gloves while placing them on your hands.

2. (1)-Open the sterilization pouch containing the falcon tube rack, remove the rack, and place it on the sterile hood table.

3. (1)-Open the sterilization pouch containing the forceps without touching the inside of the pouch and set the pouch aside.

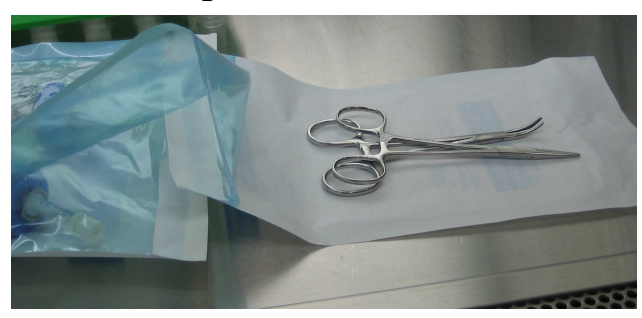

4. (1)-Open the sterilization pouch containing a bioreactor without touching the inside of the pouch.

5. (2) - Reach into this pouch and remove the bioreactor assembly. Unscrew the lid of the assembly and set aside.

6. (1) - Open sterile bag containing the gelatin tubes and hold open for (2).

7. (2) - Use curved forceps to hold the female snap connector attached to the bioreactor body.

8. (2) - Use the straight forceps to remove the gelatin tube from the open falcon tube by grabbing it by the valved male snap connector.

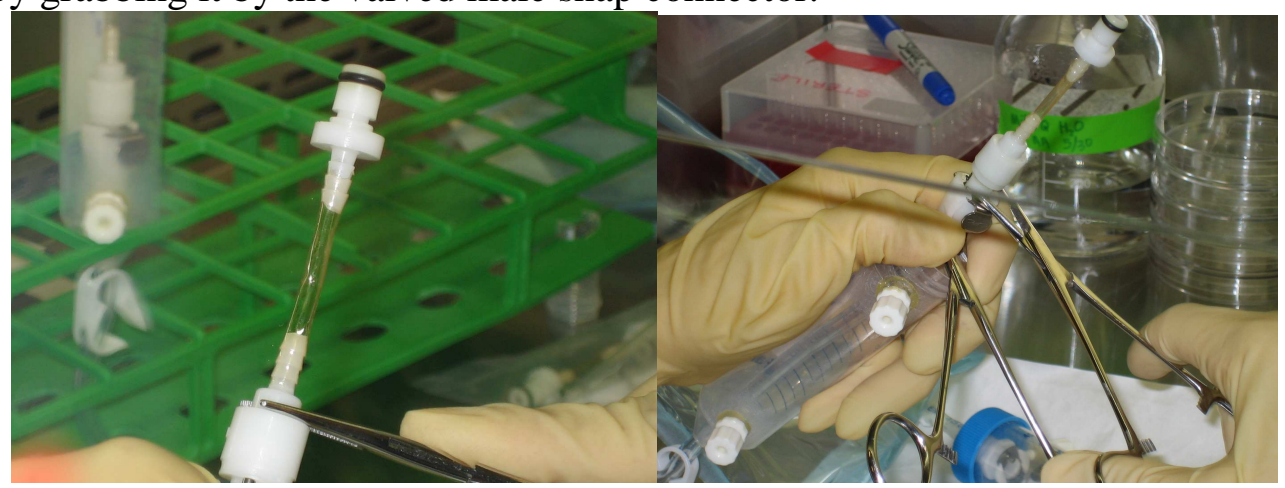

9. (2) - Snap the male valved snap connector into the female snap connector by pressing with your index finger on the pivot point of the straight forceps until the 
snap of the locking mechanism is heard (take care not to touch the inside of the bioreactor or any part of the gelatin tube assembly with anything other than the forceps). *use hand as a last resort*

10. (2) - Pull the tube attached to the female snap connector until the bottom of the non-valved male snap connector is even with the top of the bioreactor body.

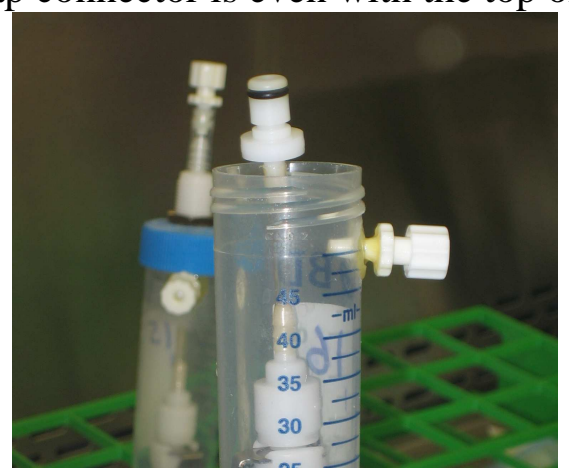

11. (2) - Place the straight forceps across the rim of the opening at the top of the bioreactor body and squeeze them such that they support the non-valved male snap connector but do not touch the gelatin tube.

12. (2) - Take the bioreactor lid and snap the non-valved male snap connector into the female snap connector on the lid by pressing the lid firmly down onto the nonvalved male snap connector until the snap of the locking mechanism is heard.

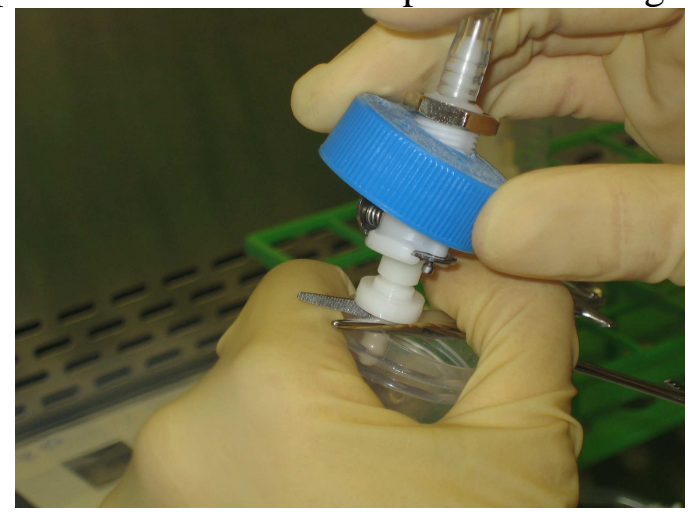

13. (2) - Pull on the tube attached to the female snap connector associated with the bioreactor body until the lid reaches the opening at the top of the bioreactor body.

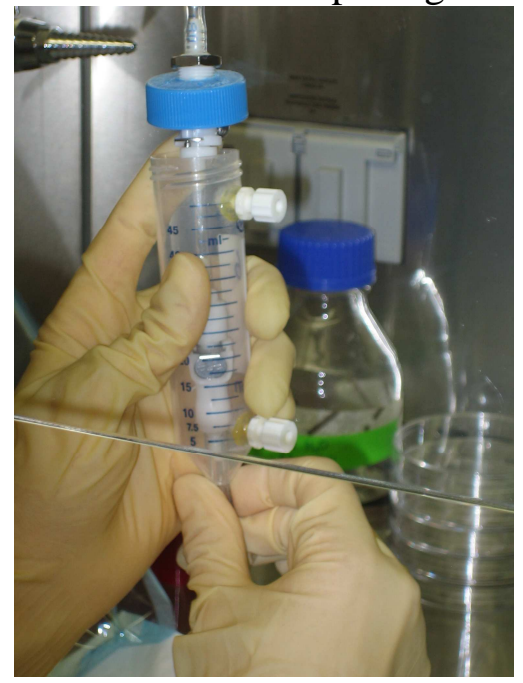


14. (2) - Screw on the bioreactor lid (not too tight) taking care not to twist the gelatin tube.

15. (2)-Screw down the nut above the lid until it is just tight.

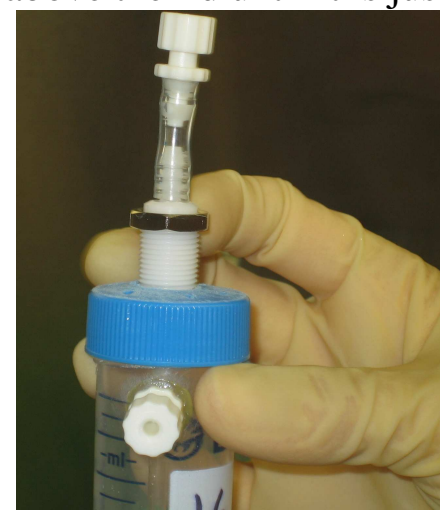

16. (2) - Slide the tube clamp as high as the bioreactor body will allow.

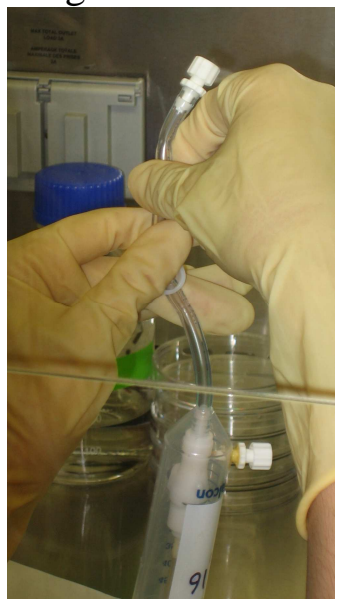

17. (1 \& 2)—Repeat steps 2-18 for each bioreactor, set aside in sterile hood until ready to start cell seeding process.

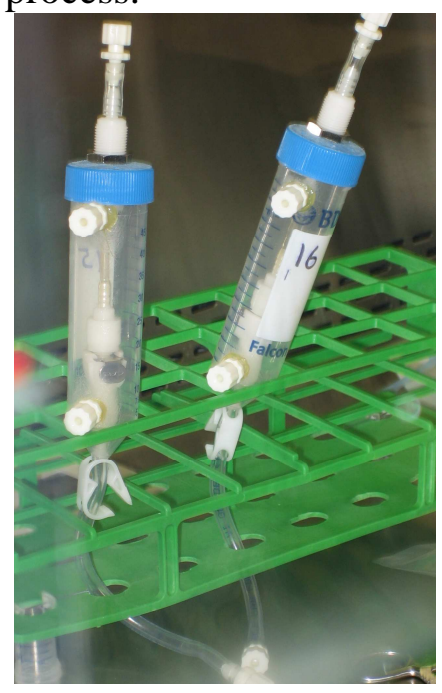




\section{Protocol for Bioreactor Cell Seeding}

Preparation

5. Clean surfaces in sterile hood with ethanol.

6. Wipe down all materials with ethanol and place in sterile hood.

7. Ensure pre-made bioreactors (w/ gelatin tubes), and sterile gloves are in the sterile hood.

Assembly (requires 2 people-denoted (1) \& (2))

1. (1) \& (2) - Open a pair of appropriately sized sterile gloves taking care not to touch the inside of the packaging or the outside of the gloves while placing them on your hands.

2. (1)-Unscrew the luer lock cap on top of the tubing that leads to the gelatin tube and set the cap, on the sterile hood table.

3. (2) - Loosen the lid of the falcon tube containing the cells (see protocol for counting cells below). Also, open a sterile $3 \mathrm{~mL}$ syringe (making sure to screw off the needle).

4. (2)-Make sure to pipette solution up and down during procedure so that cells don't

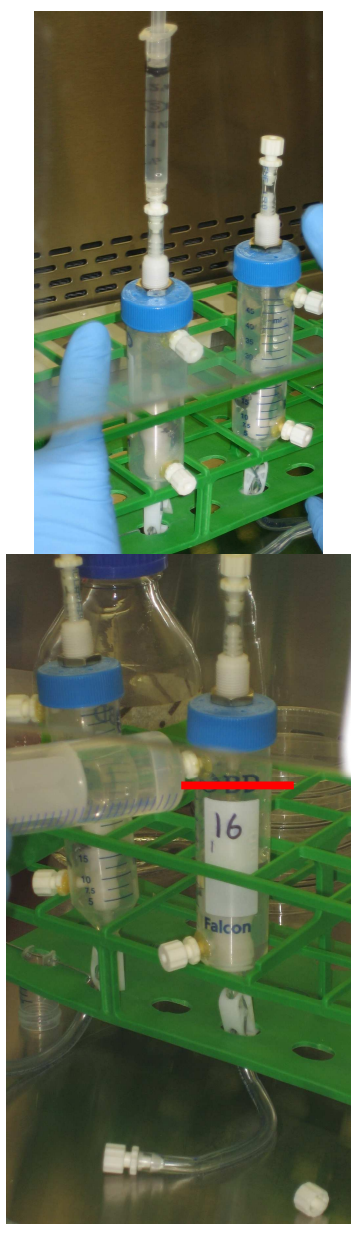
settle/bind to inside of tube.

5. (2) - Fill the syringe with the cell/media mixture and screw the syringe into the open (top) luer lock fitting.

6. (1)\&(2)-(1)Remove the luer lock cap on the end of the 6" length of tubing to allow for flow while (2) injects cells until they line the entire length of the gelatin tube and close the tube clamp to ensure flow is stopped. Make sure not to push the plunger down once clamp is closed, it will cause the gelatin tube to leak. Replace both luer lock caps.

7. (1) - Unscrew the upper luer lock cap (on the bioreactor body).

8. (2)-Open a new $50 \mathrm{~mL}$ syringe and fill with $\sim 40 \mathrm{~mL}$ of media without touching the inside of the media bottle with the outside of the syringe.

9. (2)-Screw the syringe into the open luer lock and inject the media until it is flush with the bottom of the open luer lock fitting (as illustrated by the red line).

10. (2) - Remove the syringe and replace the luer lock cap.

11. (1)\&(2)-Repeat steps 2-10 for each bioreactor. 
Cell Counting (using a hemacytometer) Procedure: done in conjunction with above

Materials:

- Hemacytometer

- Cell counter/tally clicker

- Cell culture reagents: media, PBS, Trypsin

1. Prepare hemacytometer by wiping with lens paper and ethanol. Also prepare a coverslip the same way, and place on the counting surface prior to adding cell suspension.

2. Prepare cells (on a tissue culturing plate) by first aspirating off media, rinsing cells with 2-3 mL PBS, and aspirating that off.

3. Next add 2-3 $\mathrm{mL}$ Trypsin and place in incubator $\sim 5$ minutes. After the 5 minutes, ensure cells have come off of the plate by slightly tapping the side. DO NOT aspirate off this mixture (the Trypsin will be diluted out).

4. Once cells are ready, add $\sim 10 \mathrm{~mL}$ media. Pipette up and down to mix and place mixture in a $15 \mathrm{~mL}$ falcon tube.

5. Centrifuge at 2000rpm for 2 minutes.

6. Aspirate most of media, making sure not to disturb pellet. Add appropriate amount of media to tube and resuspend cells carefully.

7. Remove $10 \mathrm{uL}$ of cell mixture, pipetting into one of the V-shaped wells of the hemacytometer. Allow mixture to flow through slide by capillary action.

\section{Counting:}

- Make sure most of grid is in focus with the $4 x$ objective (40x magnification).

- Count cells in the larger squares of the four corners, plus the large middle square. Each of the large 9 squares has a volume of $0.1 \mathrm{~mm}^{3}$ (or $10^{-4} \mathrm{~cm} 3$, $1 \mathrm{~cm}^{3}=1 \mathrm{~mL}$ ). A total of count of around 100 cells is needed for it to be statistically significant.

- Once the count is completed, the calculation process can be seen below:

$$
\begin{aligned}
& \# \text { of cells } / 0.5 \mathrm{~mm}^{3} *=\text { cells } / \mathrm{mm}^{3} \\
& \left(\text { cells } / \mathrm{mm}^{3}\right) \times 1000=\text { cells } / \mathrm{mL}
\end{aligned}
$$

(* volume of big square $\mathrm{x} \#$ of squares)

Sample calculation:

125 cells $/ 0.5 \mathrm{~mm}^{3}=250$ cells $/ \mathrm{mm}^{3}$

$\left(250\right.$ cells $\left./ \mathrm{mm}^{3}\right) \times 1000 * *=250,000$ cells $/ \mathrm{mL}$

(** conversion factor between $\mathrm{mm}^{3}$ and $\mathrm{cm}^{3}$ )

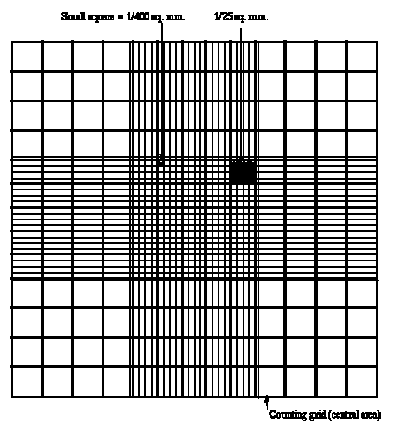

A cell count should be conducted before each cell seeding. The cell solution made need to be diluted to the same cell number for accurate results. 


\section{Bioreactor Media Protocol}

Preparation

1. Clean table in the sterile hood with ethanol

2. Wipe down all material packaging and media lid with ethanol

3. Place sterile gloves, bioreactors in falcon tube $\operatorname{rack}(\mathrm{s})$, and media in the sterile hood

Procedure

1. Open a pair of appropriately sized sterile gloves taking care not to touch the inside of the packaging or the outside of the gloves while placing them on your hands

2. Place a sterile $250 \mathrm{~mL}$ beaker underneath the bottom luer lock assembly on the bioreactor body

3. Remove the bottom luer lock cap on the bioreactor body allowing the media to drain into the $250 \mathrm{~mL}$ beaker below until all media is removed from the bioreactor. See picture below. Replace the luer lock cap.

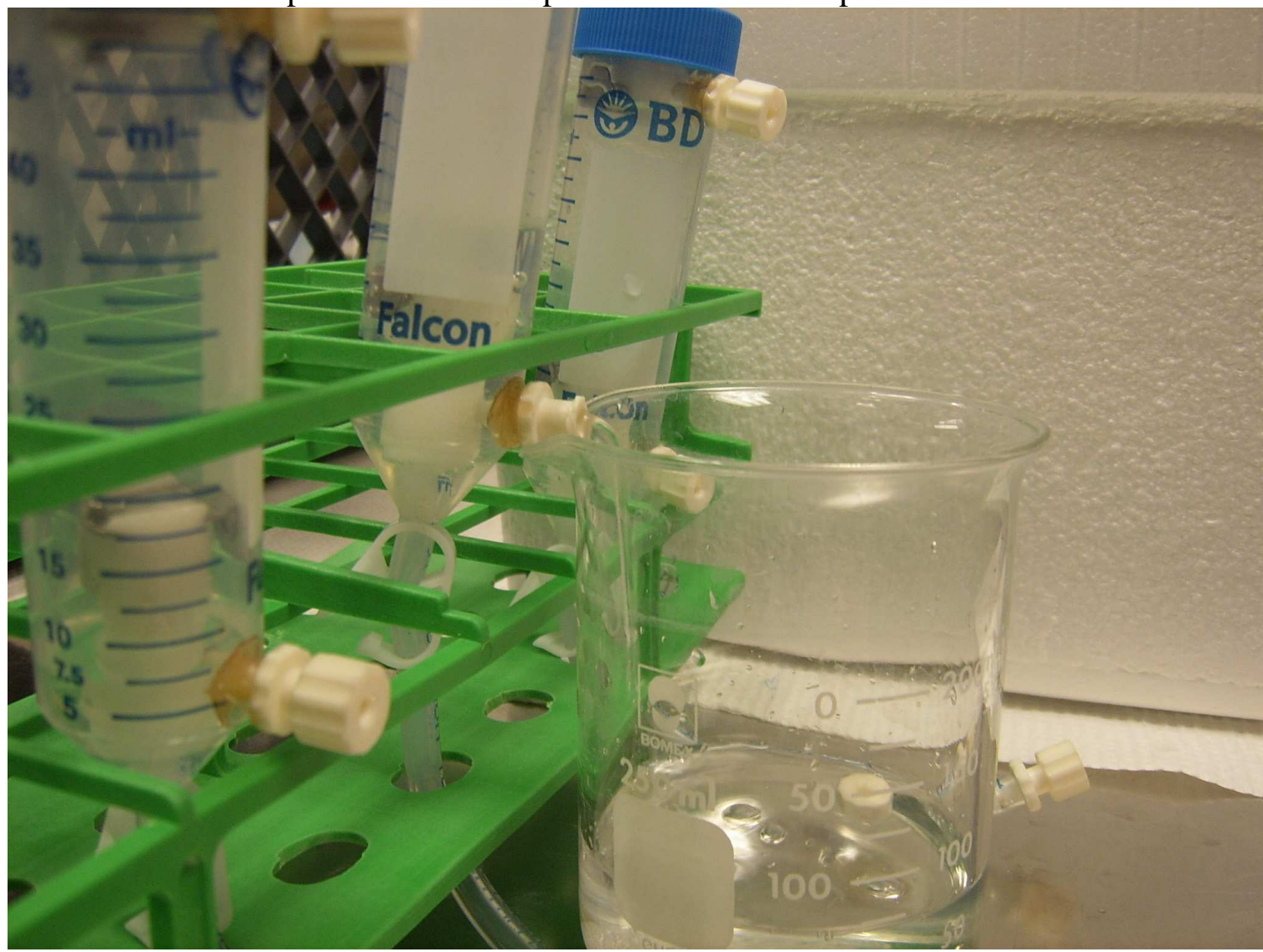

4. Remove the top luer lock cap on the bioreactor body, placing the cap, top down, on the sterile hood table

5. Open the media bottle and a new $50 \mathrm{~mL}$ syringe

6. Fill the syringe with media taking care not to touch the inside of the media bottle with the outside of the syringe

7. Take the media filled syringe and screw it into the open luer lock fitting 
8. Inject the media into the bioreactor body until the media level is flush with the bottom of the luer lock through which the media is being delivered

9. Unscrew the syringe from the top luer lock and replace the luer lock cap

10. Repeat steps 2-9 for all bioreactors, refilling the syringe as necessary to deliver the appropriate amount of media

11. Place the rack of bioreactors back in the incubator 


\section{Protocol for Plating, Splitting/Passaging, and Freezing of Cells}

\section{Plating Cells}

Materials:

Water bath (at $\left.40^{\circ} \mathrm{C}\right)$

Transfer pipettes

Falcon tubes $(50 \mathrm{~mL})$

Petri dishes $(10 \mathrm{~cm})$

Growth Media

Method:

All steps, except \#1 should be done in sterile hood.

1. Remove cryo vial containing cells from liquid nitrogen in cryo-tank and thaw in $40^{\circ} \mathrm{C}$ water. Use CAUTION: the transition from $-173^{\circ} \mathrm{C}$ to $+40^{\circ} \mathrm{C}$ can result in explosion due to rapid gas expansion

2. Transfer cells from cryo vial into the appropriate final volume of growth media

3. Pipette up and down to mix

4. Transfer the appropriate volume of cell suspension into each new plate and place in the incubator

\section{Splitting/Passaging Cells (10cm plate)}

Materials:

Aspirator

Pipette tips

PBS

Transfer pipettes

Trypsin

1000uL pipette

Growth Media

Falcon tubes $(50 \mathrm{~mL})$

Petri dishes $(10 \mathrm{~cm})$

Method:

All steps should be done in sterile hood.

1. Aspirate media, use a new pipette tip for every dish

2. Rinse culture dish with 3-4mL PBS and aspirate

3. Apply $1.5 \mathrm{~mL}$ trypsin solution to culture dish and place back in the incubator

4. Check frequently to assess cell detachment, tap side of dish to assist detachment

5. When cells detach, remove them from the dish with a $1000 \mathrm{uL}$ pipette and place in a new volume of growth media (10mL per new plate)

6. Pipette up and down to mix (using transfer pipettes)

7. Replace cells by pipetting $10 \mathrm{~mL}$ of the new cell suspension into each new $10 \mathrm{~cm}^{2}$ culture dish and place in incubator

****NOTE: Cells will need to be "fed" by changing growth media roughly every 2-3 days. Media will be an orange-like color. 


\section{Freezing Cells}

Materials:

Aspirator

Pipette tips

PBS

Transfer pipettes

Trypsin

Growth Media

1000uL pipette

Cell Freezing Media

Falcon tubes $(15 \mathrm{~mL})$

Cryo-vials

Method:

All steps should be done in sterile hood.

1. Aspirate media, use a new pipette tip for every dish

2. Rinse culture dish with 3-4mL PBS and aspirate

3. Apply $1.5 \mathrm{~mL}$ trypsin solution to culture dish and place back in the incubator

4. Check frequently to assess cell detachment, tap side of dish to assist detachment

5. When cells are detached, place them in a small volume $(5-10 \mathrm{~mL})$ of media in a $15 \mathrm{~mL}$ tube (the extra growth media will inactivate most of the trypsin).

6. Centrifuge cells for 10 minutes at $500 \mathrm{x}$ g at $4^{0} \mathrm{C}$ to form a pellet.

7. Carefully pipette the majority of the liquid off.

8. Resuspend the cell pellet in more growth media, carefully pipette up and down to mix.

9. Centrifuge cells for 10 minutes at $500 \mathrm{x}$ g at $4^{0} \mathrm{C}$ to form a pellet (this rinse removes the trypsin from the cells).

10. Carefully pipette the majority of the liquid off.

11. Resuspend the cell pellet in the appropriate volume of cell freezing media, carefully pipette up and down to mix and aliquot to cryo-vials.

12. Place in vials in $-80^{\circ} \mathrm{C}$ freezer overnight, then into liquid nitrogen storage. 


\section{Protocol for Cell Media Preparation}

**Make only as much as you need for 2 weeks at the most, numbers below need to be modified if more or less than $500 \mathrm{~mL}$ is needed.

Materials:

Dulbecco's Modified Eagle's Medium (Sigma D6434)

L-Glutamine (Fluka 49420-100g)

Insulin (CR1505A-25mg)

Fetal Bovine Serum (Invitrogen 16250-078 500mL)

Antibiotics (penicillin and streptomycin)

\section{Outside of Hood:}

1. Weigh out .25g L-Glutamine using a sterile scoop and mix with $5 \mathrm{~mL}$ of Dulbecco's Modified Eagle's Medium.

\section{Inside Hood:}

2. Once in solution, suck up L-Glutamine with a sterile syringe and filter (using syringe filter, Fisher 09-719A) into a sterile media bottle with sterile side of filter touching top of media bottle.

** When using syringe and filter unit: fill the syringe with solution to filter, remove the cover from the filter unit, attach the syringe to the filter unit \& remove from package, hold the syringe with filter pointing up and top it off by pushing a few drops thru (do NOT touch underside of filter unit - will contaminate), make sure to have the sterile side of filter touching top of media bottle while injecting the solution.

3. Add 440mL of sterile Dulbecco's Modified Eagle's Medium (Sigma D6434) with a sterile serological pipette.

4. Add $0.25 \mathrm{~mL}$ of $10 \mathrm{mg} / \mathrm{mL}$ insulin to media bottle with filtered pipette tip. (Final concentration must always be $.005 \mathrm{mg} / \mathrm{mL}$ for any volume of media).

5. Add 50mL of Fetal Bovine Serum with a sterile serological pipette.

6. Add $5 \mathrm{~mL}$ of antibiotics (penicillin and streptomycin) with filtered pipette tip.

7. Pipette up and down to mix with a sterile serological pipette.

*** Make sure to label bottle appropriately and clearly:

DMEM

$10 \%$ FBS

$1 \%$ antibiotics (pen + strep)

$5 \mu \mathrm{g} / \mathrm{mL}$ insulin

your initials

the date of preparation

"USE BY" date (2 weeks from date above)

***Store in refrigerator, media solution lasts approximately 2 weeks. 
Appendix B: Additional Images of Cells 

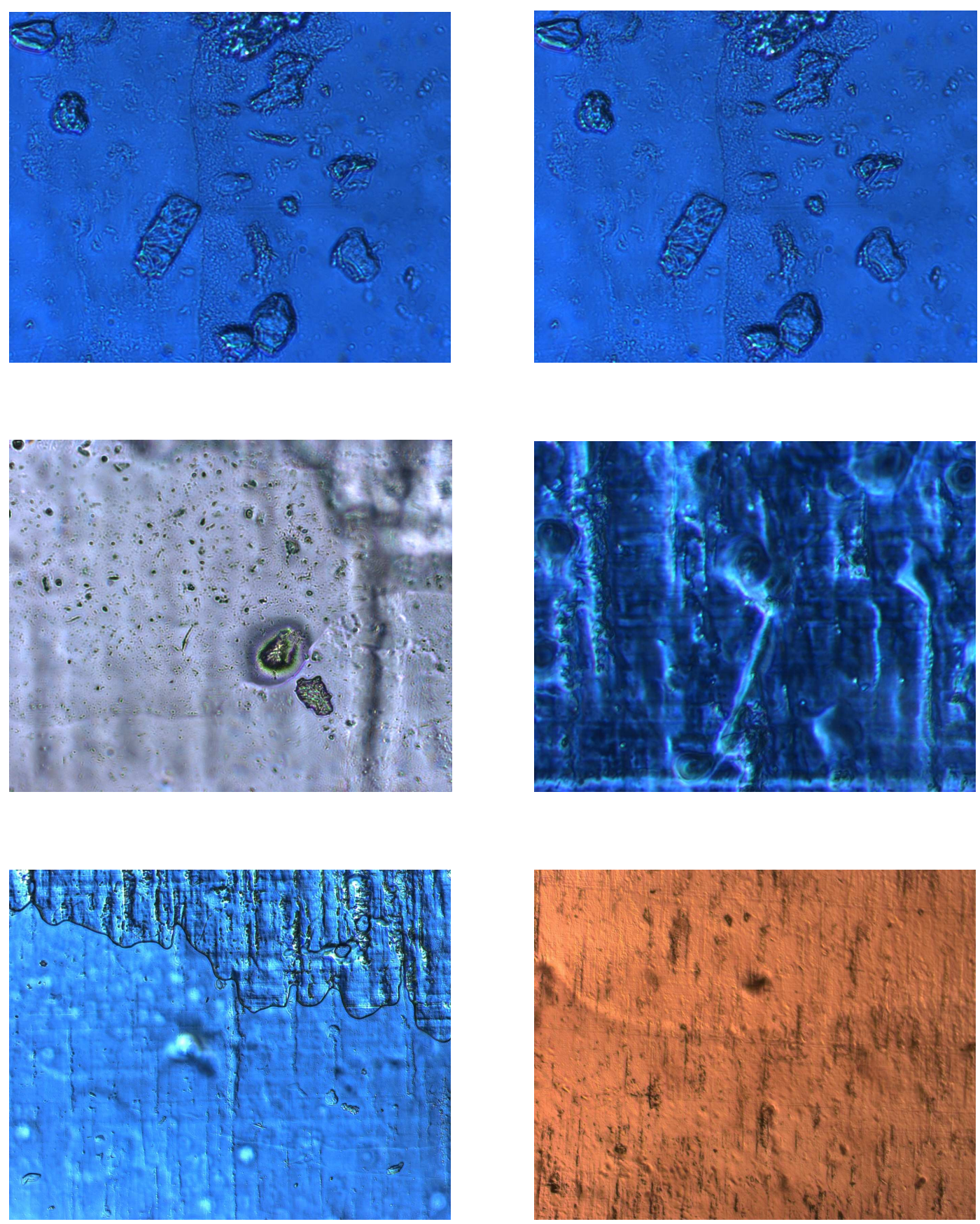

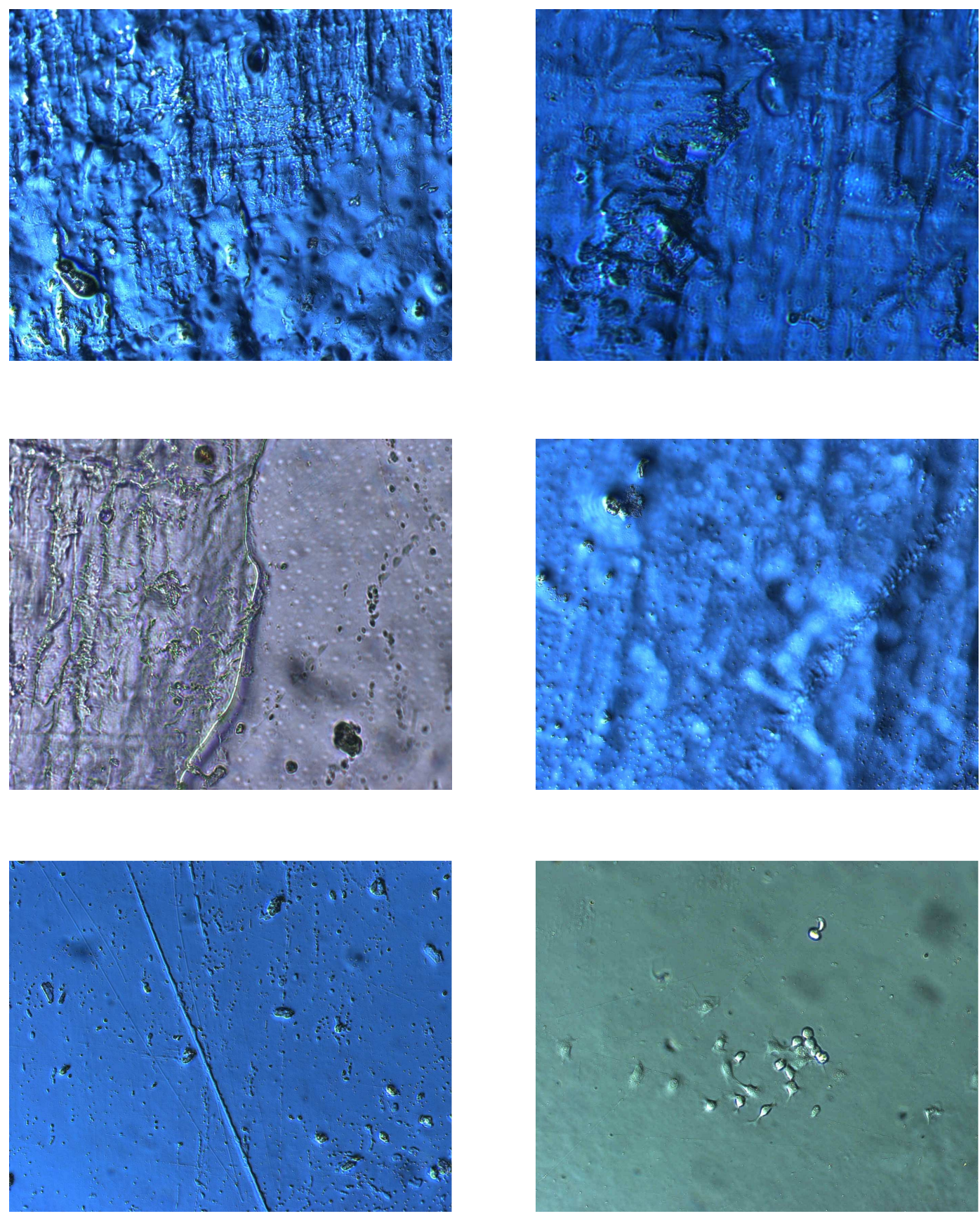